\title{
La muralla Sureste de Jaén
}

\author{
Juan Carlos Castillo Armenteros * \\ Mercedes Beatriz Luna Collantes ***
}

“... Jahen, segunt que la estoria cuenta, es villa real et de grant pueblo et bien enfortalesçida et bien encastellada de muy fuerte et de muy tenduda çerca et bien asentada et de muchas et muy fuertes torres,..".

Menéndez Pidar R. (ed.) Primera Crónica General Madrid, 1977, pág. 746

\section{INTRODUCCIÓN}

El amplio recinto amurallado de la ciudad de Jaén se completa por la zona Sureste con un sólido lienzo que ascendiendo desde la Puerta de Granada, situada en el núcleo de población, finaliza adosándose a los escarpes rocosos, que de forma abrupta, cierran la ladera Sur del Cerro de Santa Catalina. Dentro de la estructura defensiva de la ciudad medieval, la Muralla Sureste, con toda probabilidad, ha pasado a ser uno de los elementos menos conocidos ', debido a la práctica ausencia de estudios históricos y arqueo- lógicos. Sin embargo los restos aún emergentes poseen un alto valor histórico-arqueológi$\mathrm{CO}^{2}$, convirtiéndose en clara expresión del complejo sistema de defensa creado por los musulmanes para la defensa de la ciudad.

Es este breve estudio, queremos aproximarnos al conocimiento del escarpado trazado de este lienzo, para ello, utilizaremos todos los datos recogidos en las fuentes textuales (escritas y bibliográficas), así como los que aportan algunas de las intervenciones arqueológicas realizadas en los últimos años en la zona.

\section{LAS REFERENCIAS TEXTUALES}

Son diversas las fuentes textuales que destacan la inexpugnablilidad de la ciudad de Jaén, gracias a sus sólida estructura defensiva ${ }^{3}$. Sin

* Área de Historia Medieval. Grupo de Investigación del Patrimonio Arqueológico de Jaén. Universidad de Jaén.

*** Arqueóloga

I Así lo constatan las escuetas alusiones al mismo recogidas en las descripciones de aquellos autores que se han acercado a su estudio (MARTÍNEZ DE MAZAS, 1794; PI, I885; CAZABAN, 1918; 1928; CHAMORRO, 1974; PARDO, 1978; WV.AA., 1985; LÁZARO, 1988; ESLAVA, 1988a y b; 1989; 1999a y b; ULIERTE, 1990).

2 Importancia que aparece constatada en diversos estudios arquitectónicos y arqueológicos (CHIQUERO Y MORENO, 1990; CASTILLO, 1999 a y b)

3 Tanto los cronistas árabes como cristianos destacaron como una de las cualidades más representativas de la ciudad, el tamaño y la solidez de su recinto amurallado, que sin lugar a dudas estuvo dotado de diversos elementos defensivos, que fueron capaces de resistir el asedio de las tropas de Fernando III durante los tres asedios a los que sometió la plaza (GONZÁLEZ, 1946; BALLESTEROS, 1953; AGUIRRE Y JIMÉNEZ; 1979; ESLAVA, 1980; 1987), hasta que finalmente la conquistó, no por la fuerza de las armas, sino tras la capitulación negociada entre el monarca castellano-leones y el granadino. En tan sola una ocasión durante la Edad Media, las defensas de la ciudad no pudieron resistir el asalto de las fuerzas enemigas, pero a pesar de que los asaltantes penetraron en la ciudad, no lograron tomar los alcázares. Estos acontecimientos ocurrieron en I368, cuando los ejércitos del rey nazarí Muhammad V, aliado de Pedro I en su lucha contra Enrique II, lograron tal hazaña (LÓPEZ DE AYALA, I99 I; 4I0-4II; ARGOTE, I588, 482-483; ARQUELLADA, 1859, 9; 1999, 143). 
embargo, tales fuentes son enormemente parcas a la hora de describir los elementos que configuraban el sistema de defensa creado durante la Edad Media para salvaguardar la ciu$\mathrm{dad}^{4}$. Las primeras alusiones a la eficacia defensiva de los elementos que conformaban la muralla Sureste de Jaén aparecen recogidos en diversos textos escritos ${ }^{5}$, sobre todo aquellos que describen las acciones militares emprendidas por las tropas de varios Concejos de realengo, que fueron emplazados junto al camino de Granada ${ }^{6}$. No obstante, ninguno de ellos señala como estaba configurada la línea de defensa edificada en esta zona.

\section{TRAZADO}

La mayor parte de los autores a la hora de efectuar el estudio de este tramo del recinto amurallado, se limitan a señalar su ubicación sobre el actual parcelario de la ciudad y a describir de forma superficial los elementos más representativos aún conservados ${ }^{7}$. Sin embargo apenas puntualizan sobre su posible cronología, técnicas constructivas, las peculiaridades de su trazado, las distintas intervenciones ejecutadas en el mismo, o bien la configuración de los elementos, cubos, adarves, puertas y portillos, etc.

Para el estudio más o menos pormenorizado del mismo, cabría definir dos grandes zonas o sectores, que de forma continua circundaban la ciudad por su extremo Sureste:

- Sector A. Muralla de la Carrera de JesúsHuertos del Convento de la Merced. Las diferencias topográficas y altimétricas existentes en esta amplia área nos lleva a diferenciar para su análisis dos zonas:

- Tramo I: Lienzo de la Carrera de JesúsCantón de Jesús (Fig. I; Lám. I).

- Tramo ll: Lienzo de la Calle Conde-Horno Puerta Granada-Huertos del Convento de la Merced (Fig. I y 3; Lám. 2).

- Sector B. La Muralla de la Carretera Circunvalación-Afloramientos rocosos del Cerro de Santa Catalina (Fig. 2; Lám. 3).

\section{Sector A. \\ Muralla de la Carrera de Jesús. Huertos del Convento de la Merced}

\section{Tramo I}

Comprende los restos de la muralla medieval situados entre la Calle Carrera de Jesús y el Cantón del mismo nombre. Las noticias textuales señalan que el mismo arrancaba de la actual Catedral, a partir de la intercesión de las Calles Valparaiso y Almenas, en cuyas inmediaciones estuvo emplazada la torre ochavada del Alcotón. Discurría como medianera de las antiguas Casas Consistoriales (LÓPEZ, 2003;312), que reutilizaban un torreón de planta cuadrada (LÁZARO, 1988;80). Su trazado continuaba por la actual Carrera de Jesús, en cuyo tramo se documentan varias torres. La primera, se ubicaba en el solar que hoy ocupa el Ayuntamiento de Jaén, donde según S. Lázaro (1988;80) existía una torre que fue integrada en la estruc-

\footnotetext{
4 Con la excepción de las descripciones recogidas en la Crónica del Condestable Don Miguel Lucas de Iranzo, que recogen con más detalle las obras de fortificación emprendidas en 1467, las cuales se ciñeron a determinadas zonas del recinto amurallado de la ciudad (CUEVAS; DEL ARCO; DEL ARCO, 200 I, especialmente las páginas 275-276).

5 Son diversas las referencias textuales que aluden al sistema defensivo establecido en la zona Sureste de la ciudad, las más importantes aparecen recogidas en la Crónica de Ávila (1966; 42) y en la Crónica General, así como por diversos autores (ARGOTE, I588; 131), que hacen hincapié en el lugar donde se establecieron las tropas de los Concejos de Segovia, Ávila, Cuellar y Sepúlveda, en las inmediaciones de la Puerta de Granada.

6 Particularmente las huestes del Concejo de Ávila acamparon en las proximidades de las Peñas de Castro (GONZÁLEZ, 1946; 517. 5।8), quizá al amparo de las vecinas fortalezas de Castro y del Zumbel.

7 Valga como ejemplo la descripción realizada por $M^{a}$ Luz de Ulierte (1990; $\left.21-22\right)$ “...la muralla giraba de nuevo para continuar el lienzo sur donde, atravesando lo que hoy es presbiterio, sacristía y puerta sur de la catedral, enlazaba con la torre del Alcotón... Continuaba arrimada a la antigua calle Toro, abriéndose en la Puerta de San Sebastián para enlazar por el margen superior de la actual Carrera de Jesús, con torreones como el del conde de Torralba, con la Puerta de Granada, en el suroeste del recinto... A partir de ella subía la muralla entre las peñas hasta enlazarse con el Alcázar". Y muy similares son las descripciones también son las efectuadas por J. Chamorro (1973 y 1974), S. Lázaro (1988), J. Eslava (1988 y 1999), etc.
} 
tura de este nuevo edificio. Muy próximo a ella, estaba situado el Arco de Dolores o Portillo de San Sebastián, abierto en la muralla medieval a mediados del siglo XVI, con el objetivo de comunicar la zona intramuros con los espacios residenciales y agrícolas del área del Arrabal de las Monjas. Aunque actualmente, está flanqueado por un torreón circular de mampostería (Fig. 3; Lám. 4), en origen, la defensa del mismo pudo estar formado por dos cubos circulares de similar factura.

Continua la muralla sobre el amplio desnivel que presentan los edificios existentes en la margen izquierda de la Calle Obispo González, Plaza Cruz Rueda y Calle del Conde ${ }^{8}$ (Fig. I y 3), con las casas, que hasta hace pocos años, ocupaban la margen derecha de la Calle Carrera de Jesús, utilizándose el lienzo, como muro de contención y medianería. En este nuevo tramo ${ }^{9}$, aún se conserva otra torre maciza de planta semicircular (Fig. 3; Lám. 5), también de mampostería. Prosigue la muralla con un perfil quebrado para adaptándose a la orografía del terreno, no obstante, algunos intervalos han sido eliminados para convertirlos en la zona de acceso a determinadas áreas de servicio de los edificios colindantes, y del patio del Colegio Público Santo Tomás. Integrado en el recinto de esta escuela, y utilizado como muro exterior del mismo, se conserva un amplio fragmento de muralla de mampostería irregular, en el que destaca una esbelta torre cuadrada, conocida como el Torreón del Conde de Torralba (BERGES, 1973; 1986) (Lám. 6), que fue edificada con el mismo material y sillarejo en sus esquinas. Presenta un primer tramo macizo, sobre el que se eleva, a la altura del adarve, una sala abovedada, a cuyo interior se accedía a través del paso de ronda (Lám. 7). Extramuros, al pie de esta torre fue construida una de las fuentes públicas más carismáticas de la ciudad, la denominada Cañuelo de Jesús ${ }^{10}$. Esta fuente, como otras de esta zona, pudo abastecerse con el agua que suministraba el primitivo acueducto romano del Carmen 11 , que según M. López (2003;277) recogía el agua en la zona donde surgía el propio Raudal de Santa María, situado al pie de las Peñas del Arenero, junto a la actual Glorieta de Lola Torres.

Finalmente, antes de iniciar el ascenso hacia cotas más elevadas del Cerro de Santa Catalina, el lienzo se completaría con una nueva torre, que ocupaba y defendía el quiebro que en este punto realiza la muralla para iniciar el ascenso en dirección a la Puerta de Granada. Según F. Pardo (1978; 4I) era conocida como Torre de Villardompardo ${ }^{12}$, sin embargo otros autores la identifican con la Torre Sarnosa ${ }^{13}$. Los datos que sobre esta torre aparecen reseñados en la documentación escrita, nos indican, que tendría una estructura muy semejante a su vecina del Conde de Torralba, es decir,

8 Durante el desarrollo de una excavación arqueológica de urgencia realizada en el solar No 2 de la Plaza Cruz Rueda en 1993, se documento la parte alta de la muralla medieval, con un importante paquete de materiales estratificados de época medieval (PÉREZ, 1993).

9 Este fragmento ha sido recientemente restaurado por la Escuela Taller de Jaén, permitiendo no solo consolidar los restos fortificados, sino también liberarlo de una serie de edificios y viviendas familiares de pésima calidad que fueron edificadas adosadas a su base. Estos trabajos nos han permitido contemplar la propia estructura de los elementos que componen este fragmento de mura$\|$ a, construida en mampostería irregular. Sus características constructivas determinan que se trata de una obra bajomedieval, que pudo reutilizar como basamento, las antiguas zarpas de cimentación de la muralla islámica. Según S. Lázaro (1988; 80) este lienzo estaba ubicado en la propiedad de D. Yñigo de Córdoba y Mendoza al que se conceden en 1630 "los guecos de las tres torres que alindan con la muralla y también con sus casas principales la dha muralla que está frente del convento de carmelitas descalzas".

10 Actualmente desaparecida, de ella tan solo se conservan algunas antiguas fotografías, como la publicada en la página 8 del № 20 de la Revista Senda de los Huertos.

II Acueducto que S. Lázaro (1988; 32) relaciona con la existencia en este sector de la muralla de una posible coracha.

12 “...Enlazaba la muralla, este torreón (Conde de Torralba), con el conocido del Conde de Villardompardo, desde donde seguía hasta la denominada Puerta de Granada." (PARDO, 1978;4I).

13 Así lo señala Soledad Lázaro en el apartado que en su magnífico trabajo sobre la evolución de la ciudad de Jaén, dedica a las murallas islámicas "...y dando un quiebro confluía en la citada puerta (Granada), cerca de la cual se alzaba la llamada torre Sarnosa para dirigirse nuevamente en dirección al alcázar..." (LÁZARO, 1988; 32); "La documentación que hemos manejado la sitúa en el ángulo que forma la muralla al torcer desde la puerta de Granada hacia la calle Carrera de Jesús". (LÁZARO, 1988; 39). 
planta cuadrada, con una base maciza y una dependencia abovedada en la zona superior ${ }^{14}$.

Cronológicamente, la mayor parte de este tramo del lienzo Sur, pudo ser edificado entre los siglos XIV y XV sobre el antiguo trazado de la muralla islámica; de la que tan solo se reutilizó parte de su zarpa de cimentación, convertida a su vez en el basamento de las nuevas murallas de mampostería. Esta amplia reestructuración cabría relacionarla con las obras emprendidas para reparar aquellos lienzos que fueron destruidos durante algunos de los episodios bélicos vividos por la ciudad a finales de la Edad Media.

\section{Tramo II}

Desde la Torre Sarnosa partía el Tramo II de este sector del lienzo Sureste, que de forma ascendente y adaptándose al acusado desnivel que presenta el terreno en esta zona, alcanzaba la Puerta de Granada, llamada de esta manera, porque a ella llegaba el camino que unía Jaén con dicha ciudad. Todos aquellos autores que la han descrito, la definen como un amplio vano de herradura ${ }^{15}$, flanqueado por dos torres cuadradas ${ }^{16}$. Sin embargo, S. Lázaro(1988; 34) añade que tenía un trazado recto, sin recodos ${ }^{17}$. De nuevo el análisis orográfico de la zona determina la estrecha relación existente entre los muros perimetrales del actual Cantón de
Jesús y el sistema de defensa y acceso de esta puerta. Con el objetivo de salvar los acusados desniveles altimétricos que definen los primeros escarpes rocosos del Cerro de Santa Catalina y las pendientes del Barranco de los Escuderos, durante la Edad Media se construyó una amplia terraza que prácticamente circundaba todo el recinto amurallado (Carrera de Jesús), y que rápidamente fue transformada en una vía perimetral que enlazaba las puertas y los portillos de la zona entre sí, y exteriormente también éstos con las principales vías comunicación que llegaban a la ciudad. Con el objetivo de conectar esta terraza con los distintos vanos abiertos en la muralla (puertas y portillos) sobre una cota superior, se edificaron una serie de rampas transversales, delimitadas por sólidos muros de contención (los Cantones).

Por ello, con toda probabilidad todos estos elementos configuraban un acceso recto, pero que, como han puesto de manifiesto las intervenciones arqueológicas efectuadas recientemente en otras puertas de la ciudad de Jaén ${ }^{18}$, una de sus torres de flanqueo, se adelantaría, sirviendo como amplio baluarte defensivo, a la vez que contrafuerte, que impedía el desplazamiento pendiente debajo de todo el armazón de la puerta. Por tanto, esta estructura de rampa, con puerta sobre elevada, y torres retranqueadas o adelantadas, definían un acce-

\footnotetext{
14 Soledad Lázaro, considera que esta torre formaba parte del sistema de flanqueo de la Puerta de Granada, ya que por su proximidad al patio intermedio de acceso a esta puerta era denominada como "torre-corral" (LÁZARO, I988; 40). Sin embargo, si analizamos el acusado desnivel y la distancia existente entre el quiebro de la muralla y el lugar donde estuvo emplazada la Puerta de Granada, podremos considerar que la misma no formaba parte de su armazón, pero si de su sistema defensivo, ya que ésta no solo afianzaba la seguridad de la esquina del recinto amurallado, sino que también, contribuiría a incrementar la estructura defensiva construida en dicha puerta. Asimismo, esta autora apunta, que según los libros de Actas Capitulares de la ciudad de Jaén de I476, esta torre jugaría un papel importante en el control de la Puerta de Granada, ya que disponía de un cuerpo de guardia y de vigilancia permanente. Sin embargo, en épocas posteriores, cuando se desarticuló la frontera con Granada y el peligro al ataque de tropas enemigas había desaparecido, las salas superiores eran arrendadas a particulares.

15 Arco que fue demolido en 1845 (V.AA, 1985; 62).

16 Así la describen la mayoría de los autores: "...flanqueada ésta por dos torres cuadrangulares con arcos de herraduras, que daban paso al antiguo camino romano hacia la ciudad granadina..." (PARDO, 1978; 4I); "...Puerta principal ésta también, con arco de herradura entre dos torres cuadradas, constituía el límite por este lugar de la ciudad..." (ULIERTE, 1990; 22).

17 Según esta autora, el estudio que efectúa de las fuentes escritas, le permiten formular una interesante hipótesis, en la que establece la similitud que presentan en su esquema constructivo las Puertas de Granada y de Martos. Y cuyas características(puertas con acceso directo) las convertían en los puntos más débiles del conjunto defensivo, circunstancia que fue también observada por Fernando III, al dirigir contra ellos sus intentos de asalto a la ciudad. (LÁZARO, 1988; 38).

18 Sobre todo la llevada a cabo en la Puerta de Martos (BARBA ET ALII, 2003). Puerta demolida en I862 (LÓPEZ, 2003; 279) que pudo guardar enormes semejanzas con las que estudiamos, y cuya estructura aparece perfectamente definida en una fotografía de Genaro Ximénez de la Linde de 1862 (LÓPEZ, LARA Y LÓPEZ, 1999), y en una reconstrucción aproximada realizada por J. Eslava (1999;63).
} 
so prácticamente en línea recta, pero no carente de amplias posibilidades defensivas. No obstante, tenemos que tener en cuenta, que según los Libros de Actas Capitulares de la ciudad de Jaén, en 1505 esta importante puerta fue sometida a una profunda reforma, que afectó sin lugar a dudas a su esquema constructivo ${ }^{19}$.

Junto a ello, recientes investigaciones arqueológicas también han sacado a la luz los posibles restos de uno de los elementos de flanqueo de la Puerta de Granada (KAISSER Y CAMPOS, 2002; LUNA, 2002). Nos referimos a los restos de la esquina de una torre de tapial, perfectamente careada, que ocupó el flanco izquierdo de la puerta (Fig. 4, Lám. 8 A y B). Esta torre fue edificada en tapial de tierra, revistiéndose todo el conjunto con una gruesa capa de argamasa que protegía el núcleo central. Técnica que aparece documentada en otras áreas de la muralla islámica de la ciudad de Jaén (CASTILLO Y CANO, 1994) y en otros recintos amurallados musulmanes del Alto Guadalquivir, como Andújar (CASTILLO, 1991).

Una vez atravesada, se accedía a un espacio abierto, que conformaría una especie de pequeña plaza circundada por diversos edificios ${ }^{20}$, y a la que se accedía intramuros desde la Calle Conde, así lo constata una reciente excavación llevada a cabo en un solar colindante con las Calles Arco Puerta de Granada y Conde ${ }^{21}$. Este estudio confirma la existencia de varias terrazas, posiblemente creadas entre los siglos $\mathrm{XVI}$ y $\mathrm{XVII}$, que rompen la acusada orografía de la zona, $y$ finalizan en una cota inferior definiendo un espacio abierto, circundado por al menos un edificio que fue construido adosado posiblemente a la muralla, y que amortiza algunas fosas y vertederos islámicos. Este edificio podría identificarse con el corral o revellín intramuros al que hacen referencia las fuentes escritas (LÁZARO, 1988; 34).
Desde la puerta de Granada, la muralla ascendería por la ladera del Cerro de Santa Catalina adaptándose a la escabrosidad del terreno, presentando una marcada diferencia de alturas entre las cotas interiores y las exteriores. Su edificación se realizó aprovechando las fuertes quebradas, que en algunas zonas, podrían definirse como autenticas paredes verticales de roca caliza. Prueba de esta acusada adaptación, la presentan el lienzo que en la actualidad sirve de medianería entre los huertos del Convento de la Merced y las viviendas de su entorno (Lám. 2, 10 y || ). En el año 1994, como consecuencia de las obras de construcción llevadas a cabo en el solar $N^{\circ} 12$ de la Calle Horno Puerta de Granada, y de las reformas emprendidas en el Convento de la Merced, tuvimos la oportunidad de realizar un breve estudio sobre parte de este recinto (CASTILLO, 1999 a y b). En los informes emitidos señalábamos la estrecha relación existente entre los paños de muralla y la accidentada orografía que presenta la zona de estudio, con importantísimos afloramientos calcáreos, que incrementaban las dificultades a la hora de nivelar y aterrazar el terreno. En esa ocasión analizamos los restos de un amplio y grueso muro de tapial de tierra, que al igual que en los elementos aparecidos en la Puerta de Granada, también fue revestido con una gruesa capa de argamasa de cal (Fig. I, Lám. 9). Los cajones de tabiyya que constituían el lienzo fueron levantados sobre un basamento escalonado de mampostería irregular.

A partir de este punto, la accidentalidad del terreno se incrementaba, quebrando la muralla en dirección Oeste. La adaptación del recinto a los desniveles y afloramientos rocosos, obligó a la construcción de lienzos en zigzag flanqueantes (Lám. 2 y 10 B), interrumpidos en algunos puntos por algún cubo rectangular (Lám. 10 A

\footnotetext{
19 El análisis que P. Porras (1991; 84) realiza de esta documentación le lleva a considerar “...que se erigió de nuevo la propia Puerta de Granada: el 17 de febrero ordenó la ciudad al obrero que pusiera permanentemente un hombre en dicha obra para vigilar el peso de la piedra y el labrado de la misma por los maestros y otros empleados y un mes después acordaron asentar de dietas al mismo $10 \mathrm{mrs}$. Diarios en tanto durase esa obra, ocasión que aprovechó el escribano de obras, Miguel Palomino, para quejarse de su bajo sueldo, ya que a causa de las muchas obras que se hacían en la Ciudad, en sus muros y torres, su asignación no le alcanzaba ni para papel. El día de Navidad de ese año aún no se habían terminado las obras de la Puerta, por lo que los capitulares acordaron pregonar la obra de la Puerta de Granada desta Çibdad a destajo, quién la quiere tomar para la acabar de pardo de cantería...".

20 Un esquema similar mostraba la Puerta del Alcázar de la ciudad de Andújar (CASTILLO, I99I; SALVATIERRA et alli, I99I).

21 Intervención dirigida por D. Antonio Crespo, cuyos resultados están aún en vías de estudio.
} 
y II). Hasta el momento, en todo este amplio tramo, tan sólo se han identificado dos torres. La primera fue construida para defender y reforzar el citado quiebro, justo en el punto donde finaliza la Calle Horno Puerta Granada y la muralla emprende de nuevo el ascenso hacia cotas más elevadas (Fig. I; Lám. 10 A y B). La segunda se sitúa en el extremo superior del Huerto de la Merced (Fig. I; Lám. II), antes de que la muralla experimente un suave quiebro para alcanzar la Carretera de Circunvalación. Todo el tramo comprendido entre la Puerta de Granada y los Huertos del Convento de La Merced, sufrió una importante reforma constructiva en época cristiana, ya que buena parte de sus paños y una de sus torres fueron revestidos de mampostería irregular.

Aunque apenas existen indicios de la presencia de cavas, barbacanas y antemuros en la zona, la proximidad de una de las puertas más representativas de la ciudad, obligaría a la construcción extramuros de un complemento defensivo vital para incrementar su inexpugnabilidad. Son diversos los autores que al hilo de sus investigaciones, básicamente textuales, confirman la existencia de un doble recinto amurallado en la ciudad de Jaén ${ }^{22}$. No obstante, la veracidad de estos elementos también aparece registrada en las crónicas medievales, tanto en la Crónica de la Población de Ávila como en la Crónica General de España editada por Ocampo que, al describir los ataques efectuados por las tropas cristianas contra la ciudad en 1225, se alude a estas estruc- turas defensivas ${ }^{23}$. El análisis de la orografía y de algunas de las estructuras existentes en la actualidad, así como de otras desaparecidas ${ }^{24}$ tras la amplia remodelación sufrida por la antigua Calle del Juego de Pelota ${ }^{25}$, nos indican que las mismas pudieron pertenecer al dicho doble recinto. Entre ellos los muros de aterrazamiento que configuran la rampa de acceso a la zona de aparcamiento público, situado sobre las actuales cocheras del Excmo. Ayuntamiento de Jaén, e incluso en las inmediaciones del propio Torreón del Conde de Torralba. La eficacia defensiva de estos elementos (antemuros, barbacanas y fosos) se incrementaría con los marcados desniveles y pendientes que presentaban las huertas y los arrabales más inmediatos.

\section{Sector B. \\ Muralla de la Carretera Circunvalación. Afloramientos rocosos del Cerro de Santa Catalina}

Comprende el último tramo de muralla, antes de que ésta enlace con los escarpes rocosos del Cerro de Santa Catalina. La creación de la Carretera de Circunvalación abrió una importante brecha en el mismo (Lám. 12), y ha provocado importantes fracturas y desprendimientos en la base rocosa, poniendo en peligro otros elementos cercanos. Entre ellos, una torre, forrada en mampostería irregular, que por razones de seguridad, ha sido ampliamente restaurada (Torre I) (Fig. 2, Lám. I3).

22 Por su parte S. Lázaro (1988; 33) señala que “...Según la documentación municipal, la ciudad aparece amurallada con una doble cerca en todo su perímetro cuya fortaleza se ve incrementada en sus puntos más débiles por sendas barbacanas dispuestas ante las puertas principales".

23 La Crónica de Ávila alude exclusivamente a las barreras situadas en las inmediaciones de la zona del Alcázar "...E quando llegaron a las barreras fallaron los otros en muy gran prisa e fueron ferir en los moros. E dessa llegada murieron y bien doze de los moros, ed a los otros metiéronlos por el postigo del alcáçar, ansí que Estevan Domingo mató un moro antrante de la puerta. E de allí fueron los moros tan escarmentados que çerraron el postigo del alcázar a piedra e a cal, e en guissa que jamás non le abrieron mientra los de Avila se vieron allí posados...", "...otro día aguijaron a las barreras çinco caballeros de avila" (HERNÁNDEZ, 1966; 43). Sin embargo, la versión de la Crónica General de España editada por Florián de Ocampo es más prolija a la hora de aportarnos detalles sobre la composición de estos elementos externos de la cerca : "...E entonces el rey mando fincar las tiendas en el fonsario cerca de la villa. E los concejos de Segouia e de Avila e de Cuellar e de Sepoluega pasaron de la otra parte de la villa cabo la carrera que va a Granada... e conbatieronla tan de rerzio que allanaron las cauas que eran fondas: e furacaron las barbacanas: e firiense los caualleros a manteniente dentro en la baruacana. e murieron y muchos omes de cada parte. e murieron y pieça d' caualleros cristianos: e perdieronse y muchos ca los matauan de piedras y saetas que venien tan espesas como lluuia. e entonces mando el rey don Ferrando que non combatiessen..." (BALLESTEROS, 1953; 93)

24 Restos arqueológicos que aún era posible contemplar a principios del siglo XX, como lo demuestra una antigua fotografía de la Carrera de Jesús (López, Lara y López, 1999).

25 Denominación que según M. López (2003; p. 225) desde el siglo XVII se alterno con el actual de Carrera de Jesús, rebautizada por el Ayuntamiento de Jaén en 1898 con el de Calle de Juan Montilla. 
Para un mejor estudio de este lienzo, $y$ atendiendo a criterios tecnológicos y cronológicos, hemos optado por dividirlo en dos tramos.

\section{Tramo I}

De clara cronología islámica, abarca la mayor parte de este sector del Lienzo Sureste, estando formado aproximadamente por $75 \mathrm{~m}$. de muralla. Originalmente fue construido en tapial. En su fabricación se emplearon diversos materiales entre los que destacan la cal, arena, piedras de tamaño mediano y cantos. Su construcción se realizó a través de la técnica del encofrado, con cajones de tapial que parten de un cimiento de mampostería que, mediante continuos escalomanientos, se acomoda a la topografía del terreno, impidiendo en la mayoría de las zonas el contacto directo del tapial con el suelo (Lám. I 4 A y B). Sin embargo, algunos de sus elementos fueron revestidos entre los siglos XIV y XV con gruesos paramentos de mampostería irregular rejuntada con mortero de cal. En la actualidad, se ha perdido buena parte de este revestimiento, dejando al descubierto la primitiva fábrica de tapial (Lám. I4 B y C).

A partir de la mencionada torre, el primer tramo ascendía sobre los escarpes rocosos hasta enlazar con un nuevo cubo, en este caso una estructura de mampostería regular que sufrió una intensa remodelación durante la Baja Edad Media (Lám. I5 A). Reformas que consistieron en reforzar con gruesos revestimientos de mampuestos los restos de una pequeña torre maciza de tapial de argamasa. Presenta un lamentable estado de conservación ya que ha desaparecido la mayor parte de su espejo exterior, reproduciendo una superficie externa muy irregular (Lám. 15, B). Intramuros aún se conserva el podium sobre el que se apoyaba la escalera de acceso al adarve y a la azotea de la torre (Lám. I4, A).
Finalmente este primer paño finaliza en una pequeña torre cuadrada, de la que tan solo se conserva su basamento de mampostería irregular, encontrándose completamente desaparecido su alzado de tapial (Lám. I6 A y B). Entre sus restos pueden verse diversas reparaciones muy tardías, entre ellas algunos recrecidos de mampuestos rejuntados con mortero de cal. Con toda probabilidad en época islámica, este pequeño cubo, y los anteriores (Torre I y II) fueron los únicos bastiones defensivos construidos en este sector del lienzo Sureste. Incluso, esta tercera torre, podría considerarse como el último elemento defensivo edificado en esa época, antes de enlazar con los escarpes rocosos que constituyen una auténtica barrera natural en esta zona del Cerro de Santa Catalina. Sin embargo las limitaciones y problemas defensivos que presentaron estos elementos durante los asedios de la primera mitad del siglo XIII, determinaron que tras la conquista de Jaén, se ejecutasen diversas obras, cuyo objetivo era básicamente reforzar tanto los paños de muralla como torres, revistiéndolos con los citados paramentos de mampostería 26.

\section{Tramo II}

Tiene aproximadamente una extensión de $50 \mathrm{~m}$, fue edificado completamente de mampostería irregular, y al contrario que el anterior es de clara factura cristiana, presentando unas características técnicas semejantes a las empleadas en la fabricación de los paramentos que revisten las antiguas murallas islámicas. Su construcción podría considerarse como la prolongación de los elementos de fortificación del lienzo Sureste, con el objetivo de soslayar los problemas defensivos que mostró esta zona del recinto ante los empujes protagonizados por los ejércitos cristianos durante los cercos a los que sometió la ciudad Fernando III.

\footnotetext{
26 Arquitectónicamente se observa como la primitiva fábrica de ambas torres se entrelaza perfectamente con los lienzos de tapial, y como los revestimientos de mampostería, se apoyan directamente, sin ningún tipo de trabazón, tanto las murallas como en las torres. Asimismo, algunos de estos revestimientos también alcanzaron la parte superior de los lienzos de tapial, utilizándose la coro-
} nación de la muralla islámica como el paso de ronda, y los nuevos muros de mampostería como antepechos del lienzo. 
Para cerrar este relativo punto débil de sus defensas, se optó por edificar una gruesa muralla de mampostería, que aprovechara al máximo los numerosos y significativos escarpes rocosos, que en esta zona aún no alcanzan las dimensiones de cotas superiores, ya que nos encontramos en punto donde se inicia la gran falla del Cerro de Santa Catalina (Lám.3, 17 y 18). Por ello los lienzos presentan la peculiaridad de carecer de zarpa de cimentación al levantarse directamente sobre la roca.

Esta nueva muralla, tampoco mantiene la misma trayectoria que la anterior, ya que a partir del punto de contacto de ambos tramos, se genera un cierto retranqueo del nuevo lienzo hacia el interior, motivado por la marcada adaptación de la cerca a la orografía, hasta el punto que la línea de muralla sigue tajantemente la orientación que marca el borde superior de la falla (Fig. 2; Lám. 3 y 17).

De forma accidentada esta primera parte del Tramo II finaliza en una amplia torre de mampostería, que presenta algunos problemas de interpretación (CHIQUERO Y MORENO, 1990, Ficha $N^{\circ} 59$ ), ya que tan solo se conserva parte de su basamento, $y$ ha perdido completamente sus paramentos de cierre (Lám. 18 y 19), quizá porque en su interior fue utilizado como plataforma sobre la que se elevó una torreta de alta tensión. Desconocemos cuales pudieron ser sus dimensiones originales, no obstante, un análisis detenido de sus paramentos y de los elementos conservados, nos llevan a identificarla con una torre hueca de planta cuadrada. E incluso proponer, que su interior albergó el trazado en codo de un pequeño portillo.

Finalmente, este lienzo de mampostería continuaba su ascensión hasta culminar en una plataforma de planta irregular, de la que se conserva un basamento de mampostería que define una pequeña terraza con esquina biselada (Lám. 20 A y B), que se adapta a las fracturas y afloramientos de la roca. Aunque ha desaparecido prácticamente todo su alzado, creemos que esta estructura estaría coronada por un simple antepecho, sin que alcanzara proporciones similares a las de una torre. A partir de este punto, y como consecuencia de las dimensiones y altura que adquiere el farallón rocoso, finalizan las estructuras edificadas, dando paso exclusivamente a la defensa natural del cerro (Fig. 2; Lám. 3).

\section{BIBLIOGRAFÍA}

AGUIRRE SÁDABA, FJ. Y JIMÉNEZ MATA, MC. Introducción al Jaén islámico. Jaén, 1979.

ARGOTE DE MOLINA, G. Nobleza de Andalucía. Edición de Riquelme y Vargas Ediciones SL. Jaén, 199I.

ARQUELLADA, J. de Anales de Jaén. Estudio, edición y notas de M. González Jiménez, Granada, 1996.

ARQUELLADA, J. de Sumario de proezas y casos de guerra. Estudio y edición de E. Toral y Peñaranda. Jaén, 1999.

BARBA, V.; ALCALÁ, F.; ARIAS, F.; NAVARRO, M. Y HERRANZ, AB. Informe de la excavación arqueológica de urgencia en el espacio público de la Puerta de Martos de Jaén. Archivo de la Delegación Provincial de Cultura de la Junta de Andalucía en Jaén, 2003. Inédito.

BALLESTEROS GABROIS, M.: "La conquista de Jaén por Fernando III el Santo". Cuadernos de Historia de España XX. Buenos Aires pp. 62-138.

BERGES, L. "Restauración del torreón llamado del Conde de Torralba del recinto medieval de la ciudad de Jaén". Castillos de España, N 12, Madrid (1973), pp. 52-53.

BERGES, L. "Un tramo de la muralla sur de Jaén". Senda de los Huertos. N 7, Jaén (1986), pp. 55-66.

CAÑETE, M. "El Arco de los Dolores". Revista La Alambra, III, (| 840), pp. 358-359.

CASTILLO ARMENTEROS, JC. "Excavación arqueológica de urgencia realizada en el solar sito entre las calles Alcázar-Altozano Deán Pérez de Vargas y Parras, de la localidad de Andújar (Jaén)". Anuario Arqueológico de Andalucía 1989. Tomo III, Sevilla (199|), pp. 276-29I.

CASTILLO ARMENTEROS, JC. "Informe técnico sobre los restos arqueológicos del solar sito en la Calle Horno Puerta de Granada de Jaén". Anuario Arqueológico de Andalucía 1994. Tomo III, Sevilla (1999), pp. 254-258.

CASTILLO ARMENTEROS, JC. "Excavación arqueológica de apoyo a la restauración en la Iglesia de la Merced de Jaén". Anuario Arqueológico de Andalucía 1994. Tomo III, Sevilla (1999), pp. 242-249.

CASTILLO ARMENTEROS, JL. Y CANO CARRILLO, J. Diagnosis arqueológica en la Muralla Norte de Jaén. Archivo de la Delegación Provincial de Cultura de la Junta de Andalucía en Jaén, Jaén, 1994. Inédito. 
CAZABÁN, A. "Jaén Viejo. Callejones, torres y murallas". Don Lope de Sosa, N 69, Jaén (1918), pp. 276-278.

CAZABÁN, A. "Jaén bien encastillado". Don Lope de Sosa. N | 88, Jaén (1928), pág. 225.

CAZABÁN, A. "El torreón del Conde de Torralba". Don Lope de Sosa. № 211, Jaén (1930), pág. 210.

CHAMORRO LOZANO, J. Guía artística y monumental de la ciudad de Jaén. Jaén, 197I.

CHAMORRO LOZANO, J. "Las murallas de Jaén". Castillos de España. No 79, Madrid (1973), pp. 50-5 I.

CHAMORRO LOZANO, J. El castillo y las murallas de Jaén. Granada, 1974.

CHIQUERO, E. Y MORENO, E. Ficha Técnica del conjunto defensivo de la ciudad de Jaén. Jaén, Inédito.

CUEVAS, J. DEL ARCO, J. Y DEL ARCO, J.: Relación de los hechos del muy magnífico e mas virtuoso señor, el señor D. Miguel Lucas, muy digno condestable de Castilla. Jaén, 2001 .

ESLAVA GALÁN, J. "La reconquista en la actual provincia de Jaén". Historia y Vida. No I50, Barcelona (1980), pp. $21-23$.

ESLAVA GALÁN, J. "La campaña de 1225 y el primer cerco de Jaén por Fernando III". Boletín del Instituto de Estudios Giennenses. N 132, Jaén (1987) pp. 23-38.

ESLAVA GALÁN, J. "Las murallas de Jaén". Senda de los Huertos. N I0, Jaén (1988a).

ESLAVA GALÁN, J. "Las defensas almorávides de Jaén". Boletín del Instituto de Estudios Giennenses. Jaén (1988b), pp. 9-32.

ESLAVA GALÁN, J. "Castillos y Murallas de la ciudad de Jaén". Senda de los Huertos, No I 5; Jaén (1989), pp. 35-45.

ESLAVA GALÁN, J. Los castillos de Jaén. Granada, 1999a.

ESLAVA GALÁN, J. Castillos y atalayas del Reino de Jaén. Granada, 1999b.

GONZÁLEZ, J. Reinado y Diplomas de Fernando III. Córdoba, 1980.

GONZÁLEZ, J. "Las conquistas de Fernando III en Andalucía". Hispania, XXV, Madrid (1946), pp. 5I5-605.

HERNÁNDEZ SEGURA, A. (Ed.) Crónica de la población de Ávila. Valencia, 1966.

KAISER MATA, A. Y CAMPOS LÓPEZ, T. Intervención arqueológica de urgencia de la Calle del Conde No 8 de Jaén. Archivo de la Delegación Provincial de Cultura de la Junta de Andalucía en Jaén (2002). Inédito.
LÁZARO, S. Desarrollo histórico del casco urbano de Jaén hasta 1600. Ed. Colegio Oficial de Aparejadores y Arquitectos Técnicos de Jaén. Jaén, 1988.

LÓPEZ DE AYALA, P. Crónicas. Edición, prólogo y notas de José Luis Martín. Barcelona, 199I.

LÓPEZ PÉREZ, M. El viejo Jaén. Jaén, 2003.

LÓPEZ MURILLO, J.; LARA MARTÍN-PORTUGUÉS, I. Y LÓPEZ PÉREZ, M. Jaén en blanco y negro. Introducción para una historia de la fotografía en Jaén (1860-1960). Jaén, 1999.

LUNA, MB. Informe de la Intervención Arqueológica de Urgencia en la calle Del Conde $N^{0} 8$ de Jaén. Archivo de la Delegación Provincial de Cultura de la Junta de Andalucía en Jaén (2002). Inédito.

MARTÍNEZ DE MAZAS, J. Retrato al natural de la ciudad y término de Jaén. Ediciones el Albir, Barcelona, 1978.

PARDO CRESPO, JM. Evolución e historia de la ciudad de Jaén. Jaén, 1978.

PÉREZ MARTíNEZ, MC. Excavación arqueológica de urgencia en el solar $n^{\circ} 2$ de la plaza Cruz Rueda de Jaén. Archivo de la Delegación Provincial de Cultura de la Junta de Andalucía en Jaén. Inédito

PI MARGAL, F. España. Sus Monumentos y Artes - Su Naturaleza e Historia. Granada, Jaén, Málaga y Almería. Barcelona, 1885.

PORRAS ARBOLEDAS, P. "El poblamiento de los arrabales de Jaén bajo los Reyes Católicos". Senda de los Huertos. N 21, Jaén (199|), pp. 79-93.

SALVATIERRA, V.; CASTILLO, J.C. y CASTILLO, JL. "Arqueología urbana e historia. El caso del Jaén islámico" I Coloquio Hispano-italiano de Arqueología Medieval. Granada, (1992), pág. 109-117.

SALVATIERRA, V.; CASTILLO, JC;; PÉREZ, MC. Y CASTILLO, JL. "El desarrollo urbano en al-Andalus. El caso de Andújar". Cuadernos de Madinat al-Zahra'. Vol. 2, Córdoba (1991), pp. 85-107.

SALVATIERRA, V.; PÉREZ, MC:; CASTILLO, JL; ALCÁZAR, EM. Y CANO, J. "Formación y evolución de una ciudad islámica: Jaén". Actas del IV Congreso Arqueología Medieval Española. Tomo II, Alicante, 1993. pág. 87-95.

ULIERTE, L. de. Jaén: la ciudad y su historia. Centro de Estudios Municipales y de Cooperación Interprovincial, Granada, 1990.

V.AA. Catálogo monumental de la ciudad de Jaén y su término. Jaén, 1985. 


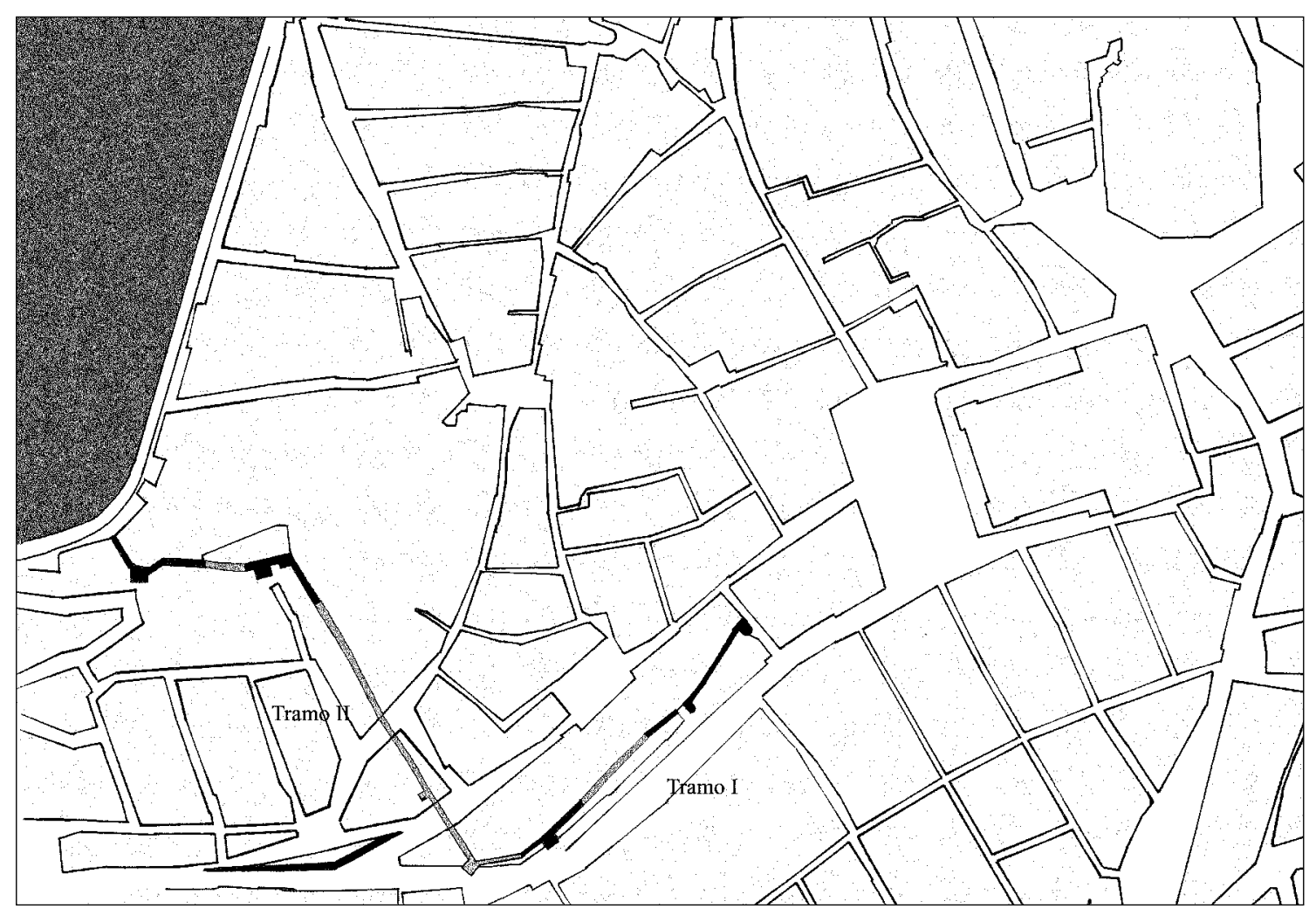

Figura $I$.

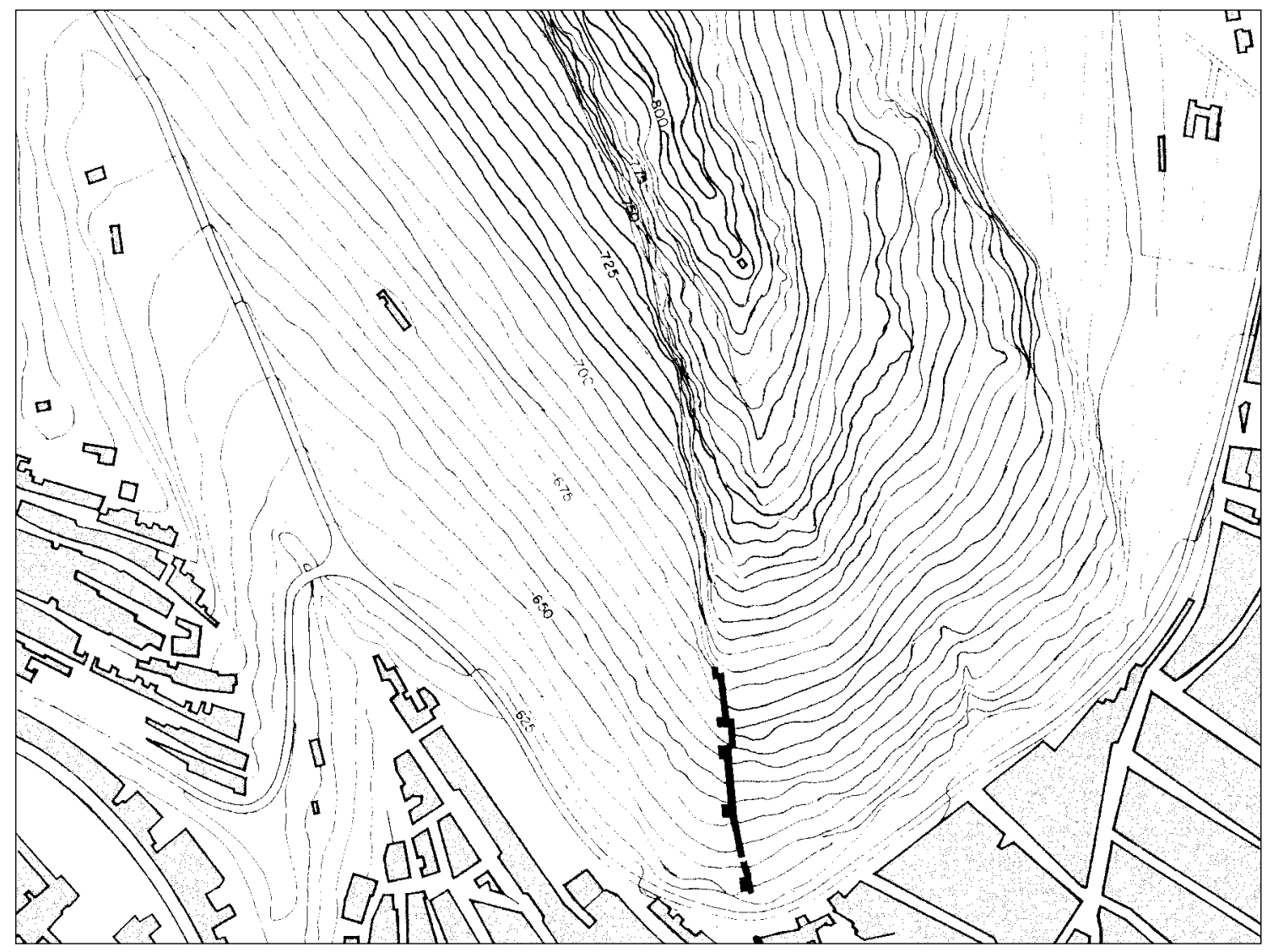

Figura 2. 


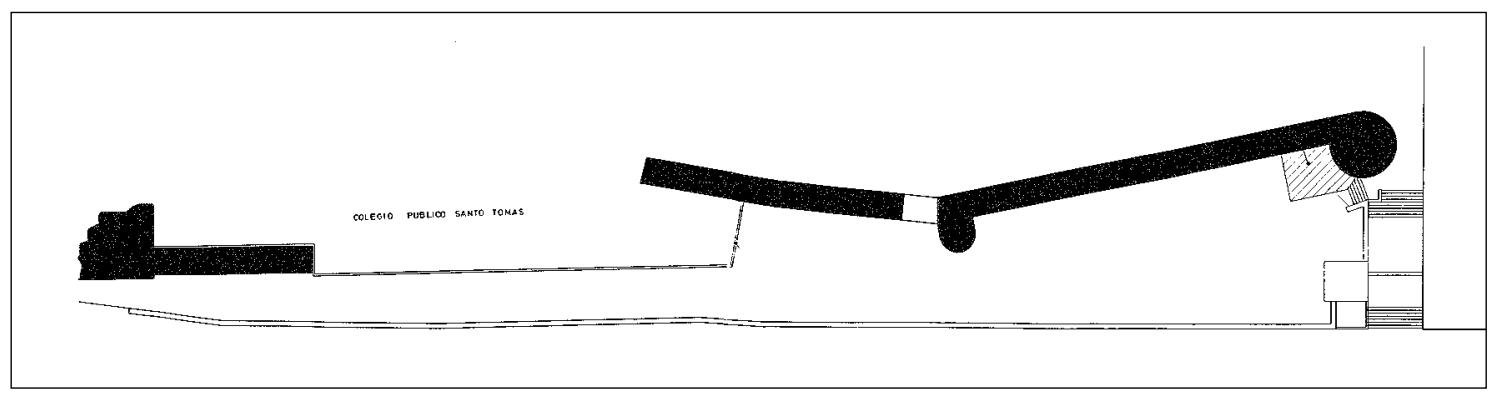

Figura 3.

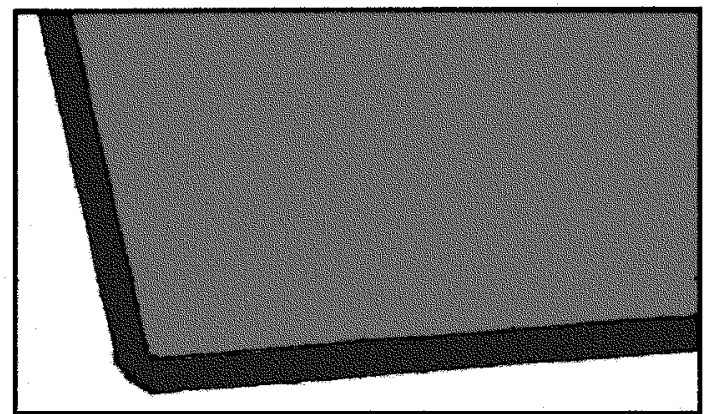

$0 \square 1$ metro

Figura 4.

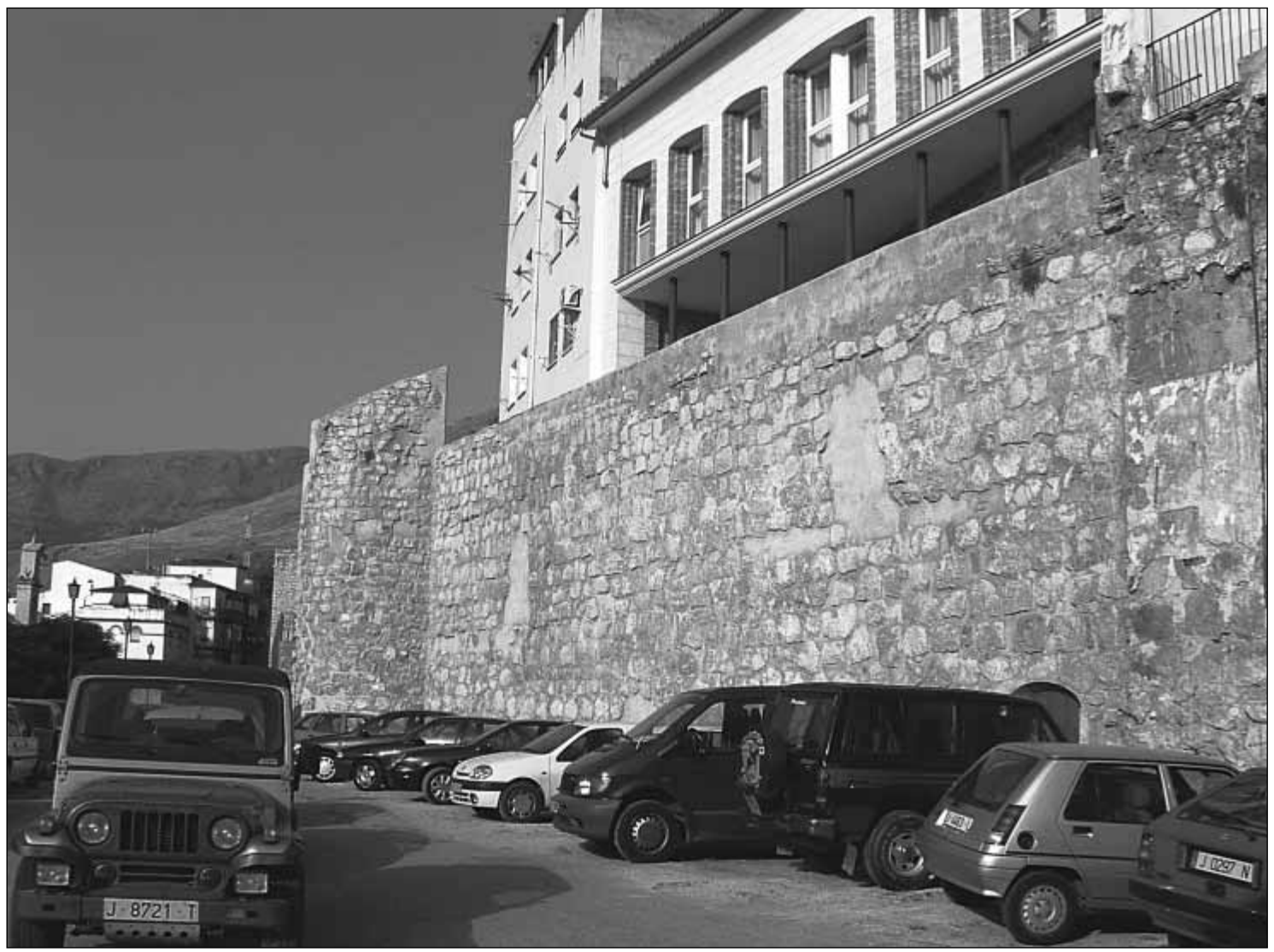

Lámina I. 

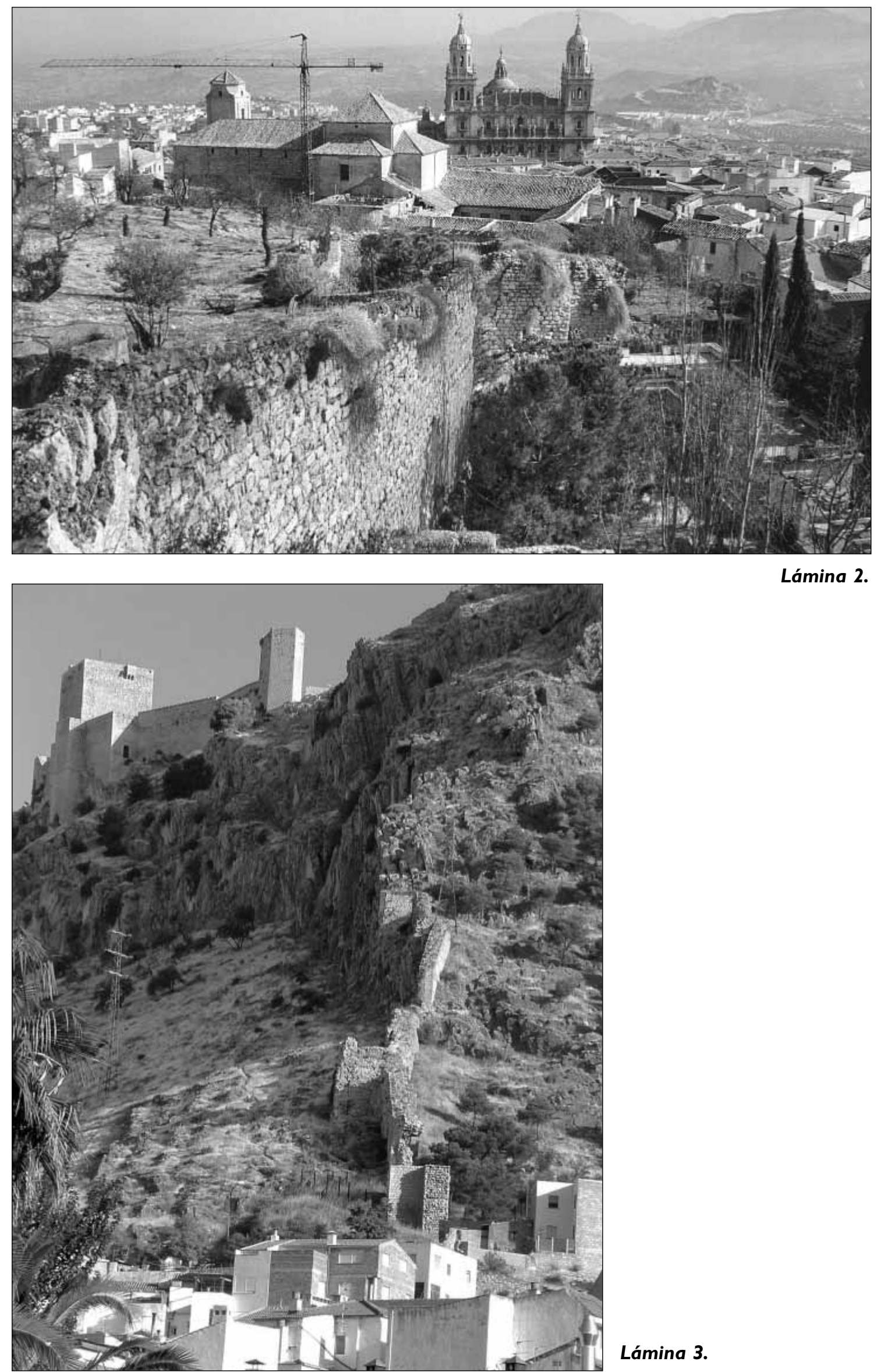

Lámina 2.

Lámina 3. 


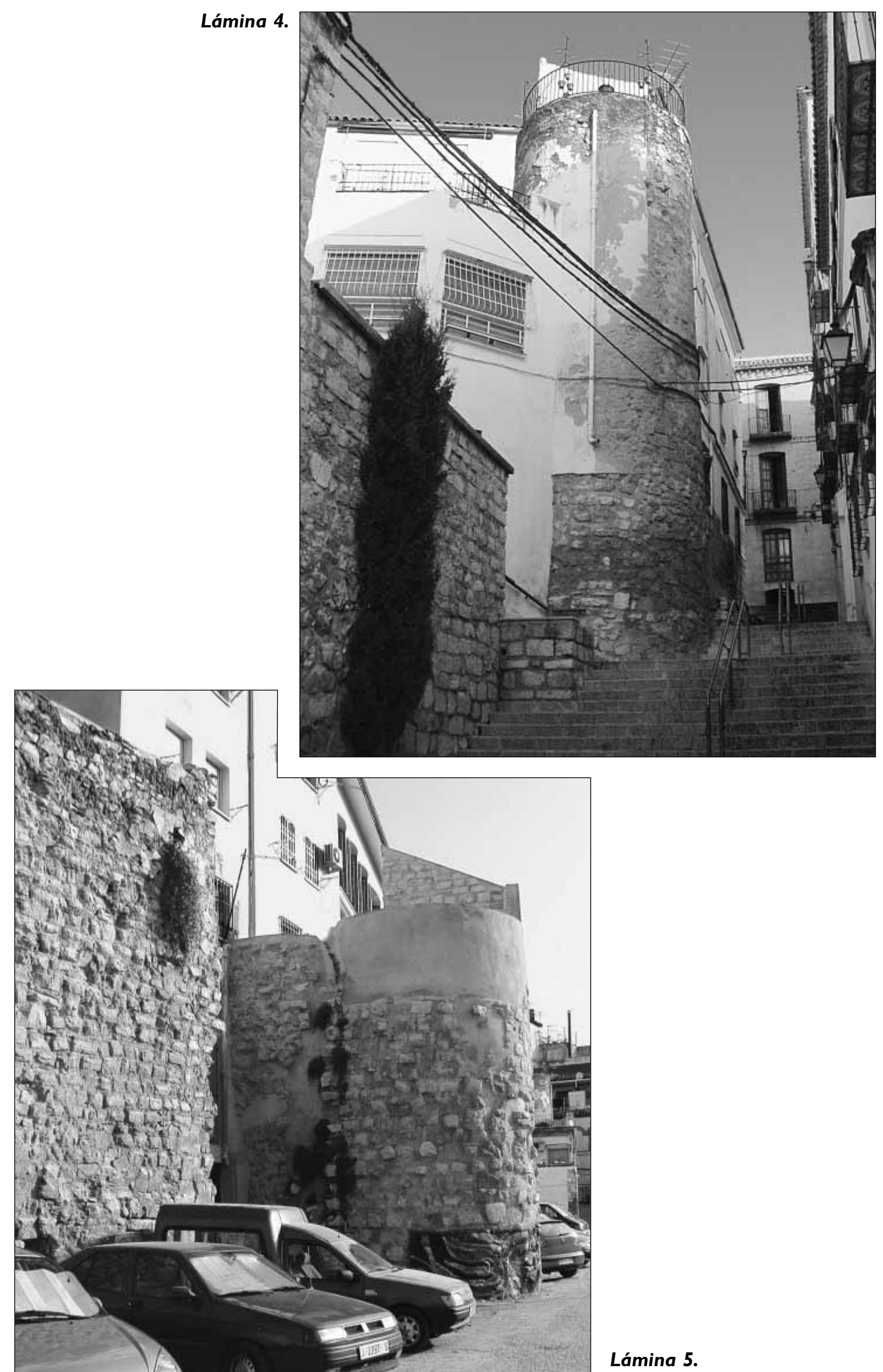




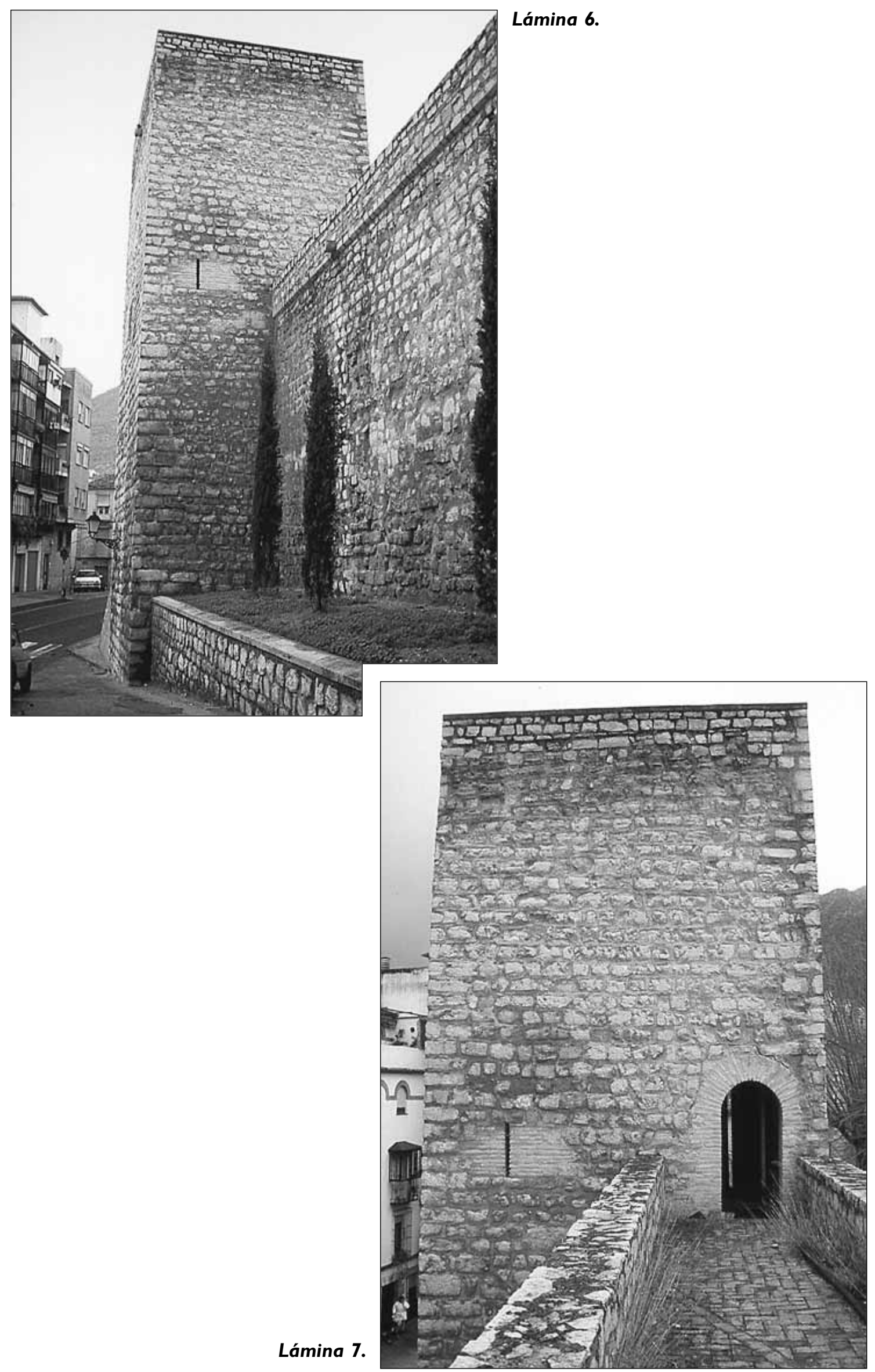




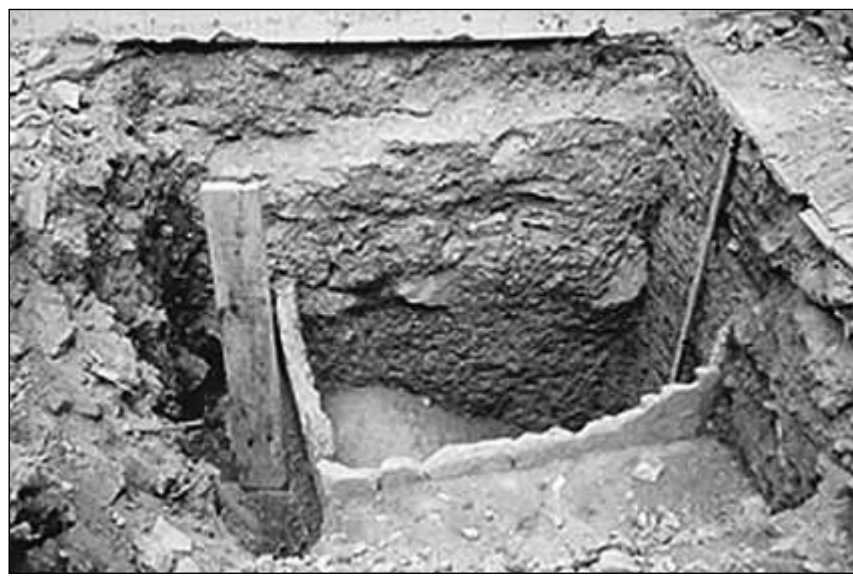

Lámina $8 a$.

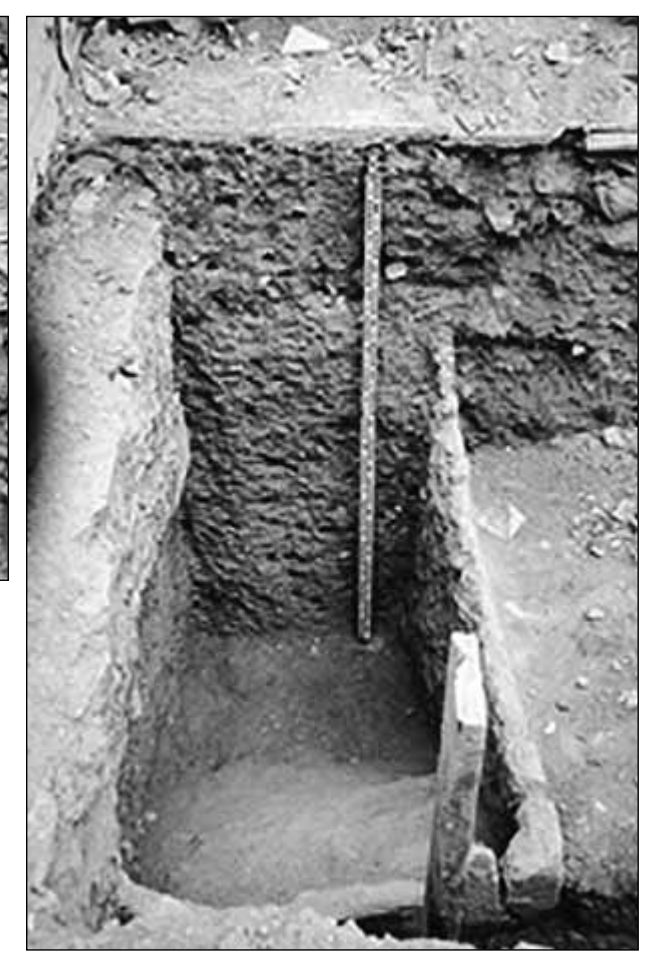

Lámina 8 b.

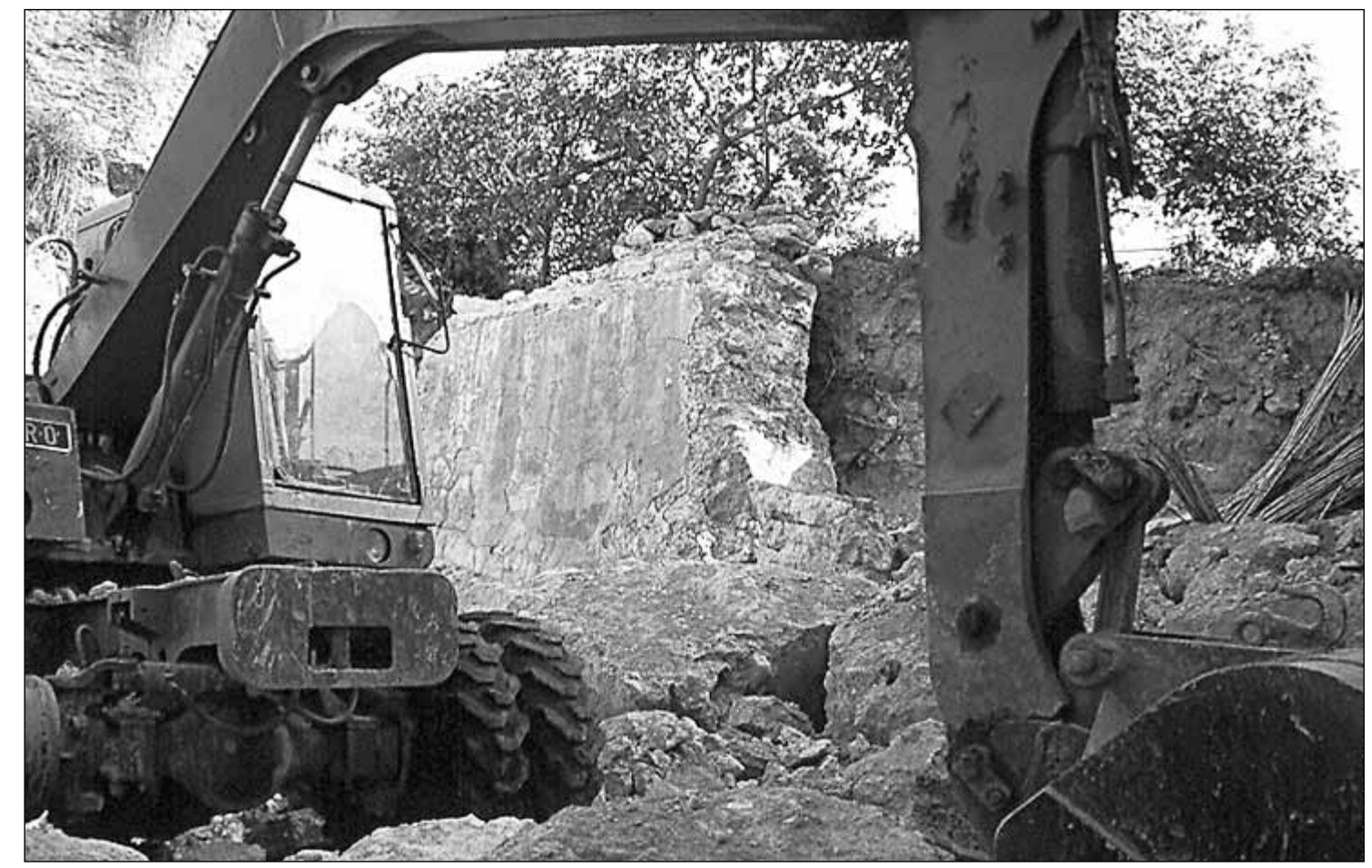

Lámina 9. 


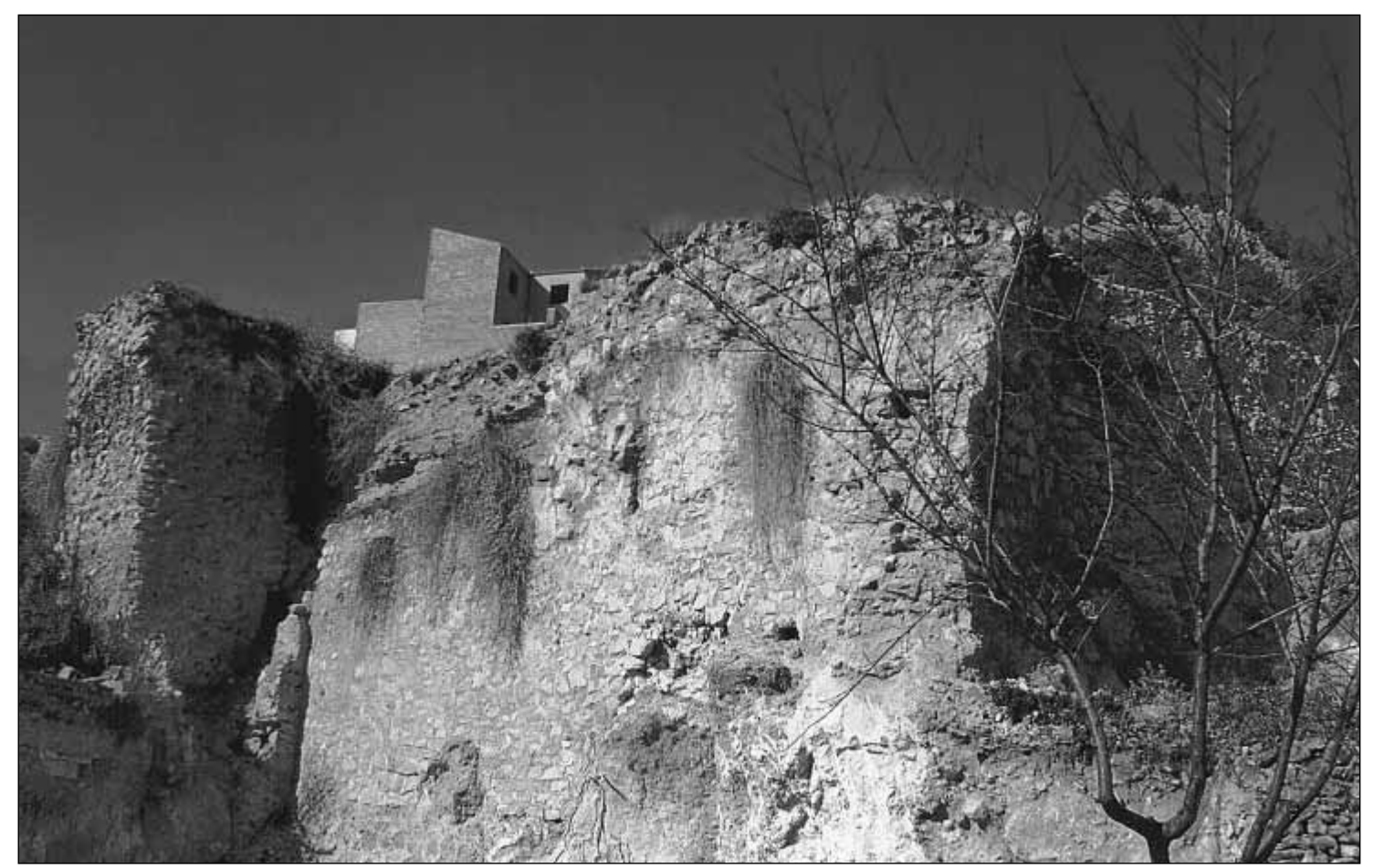

Lámina IOa.

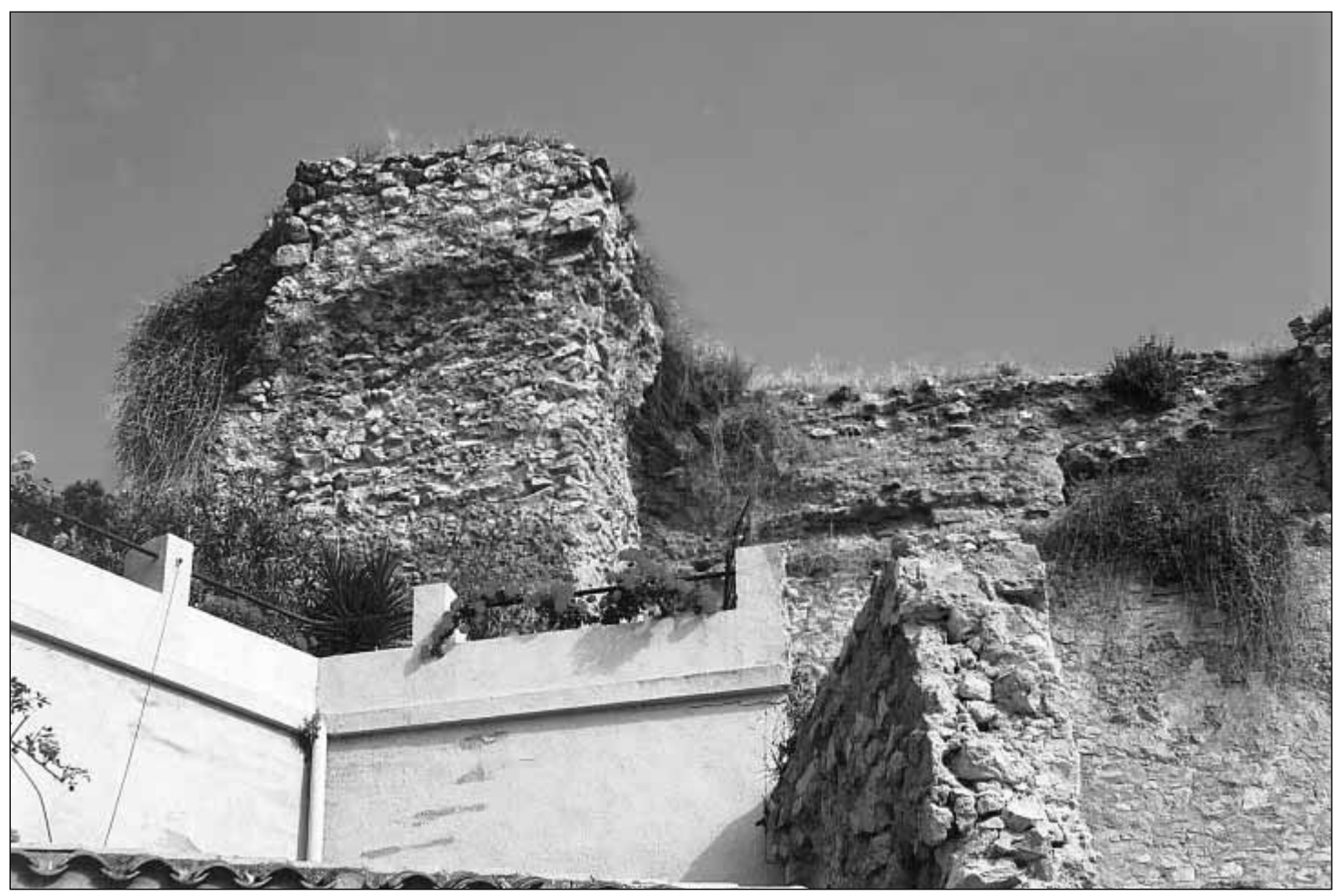

Lámina IOb. 


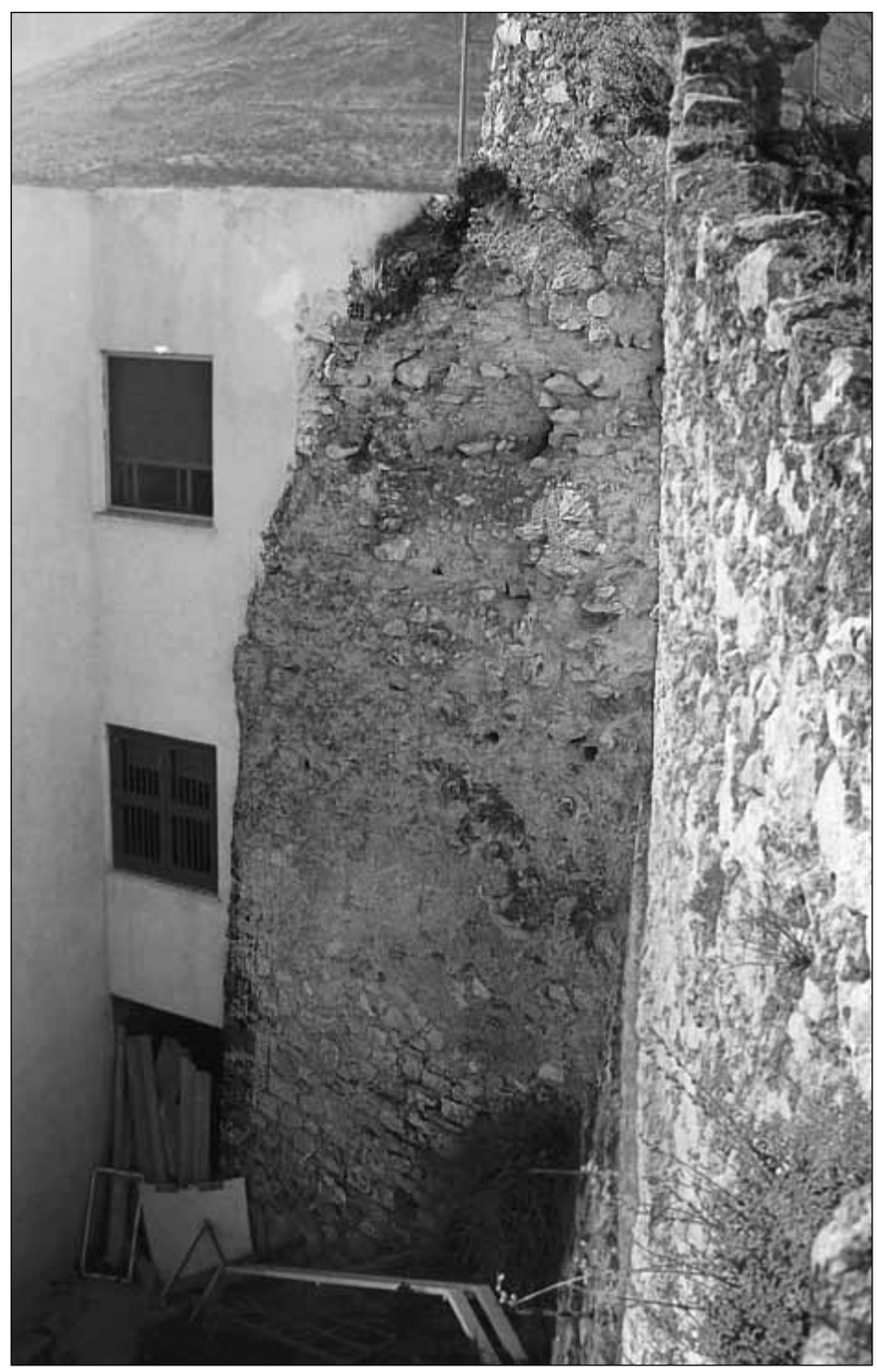

Lámina II.

Lámina I2.

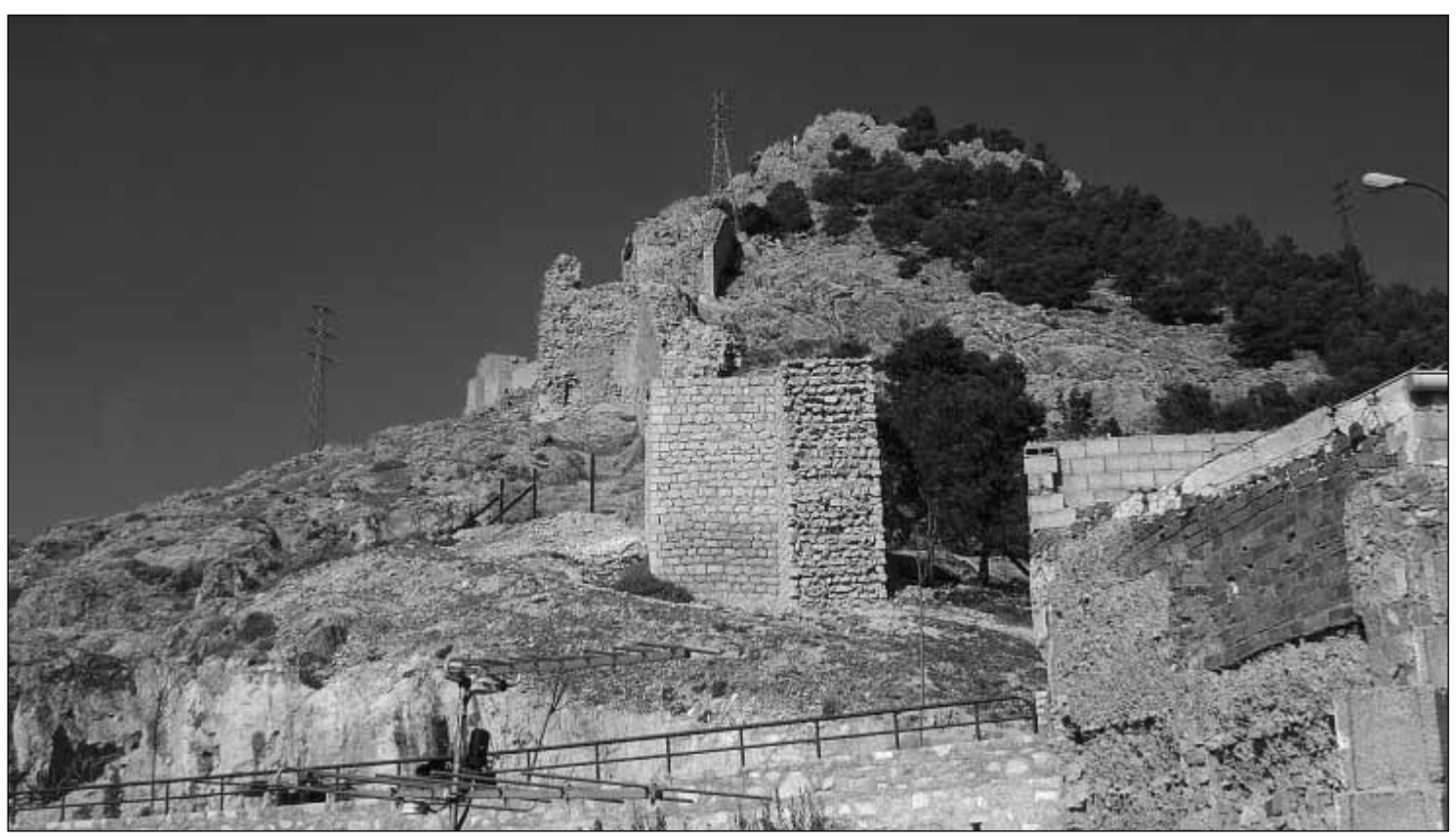




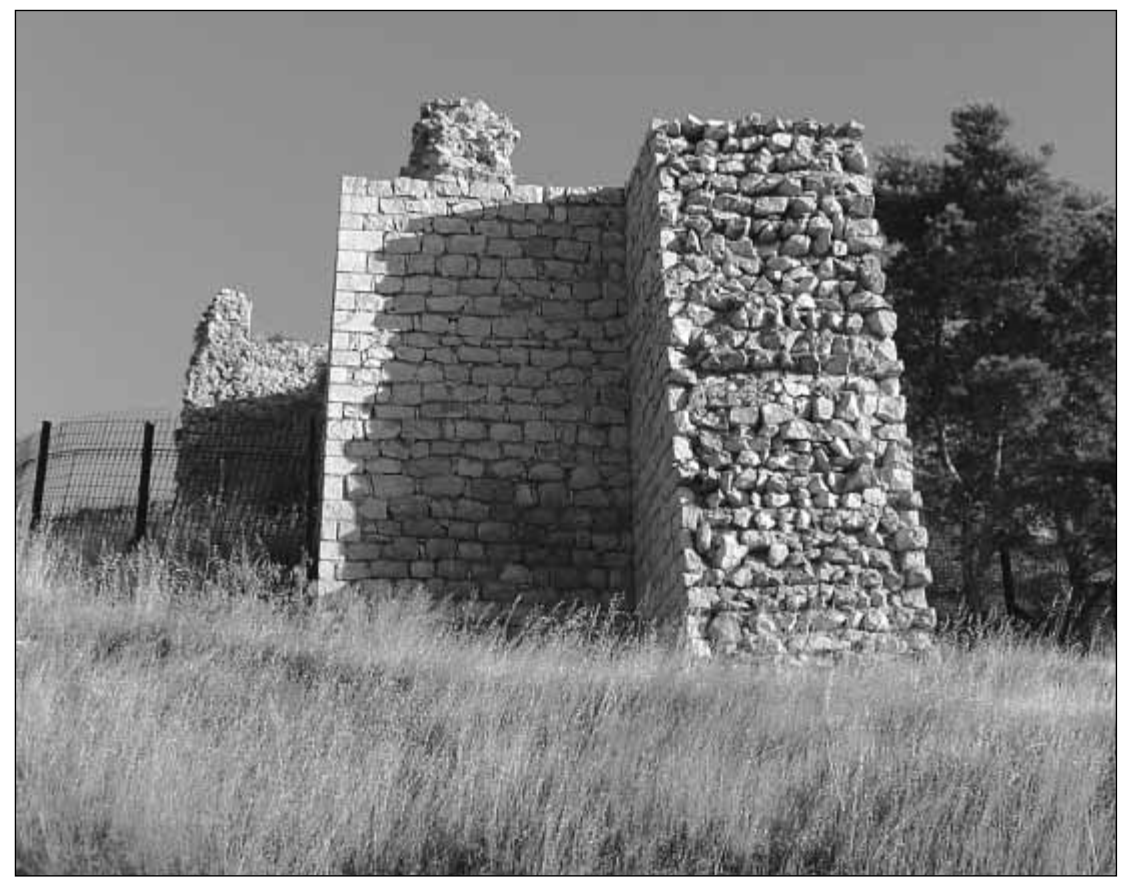

Lámina I3.

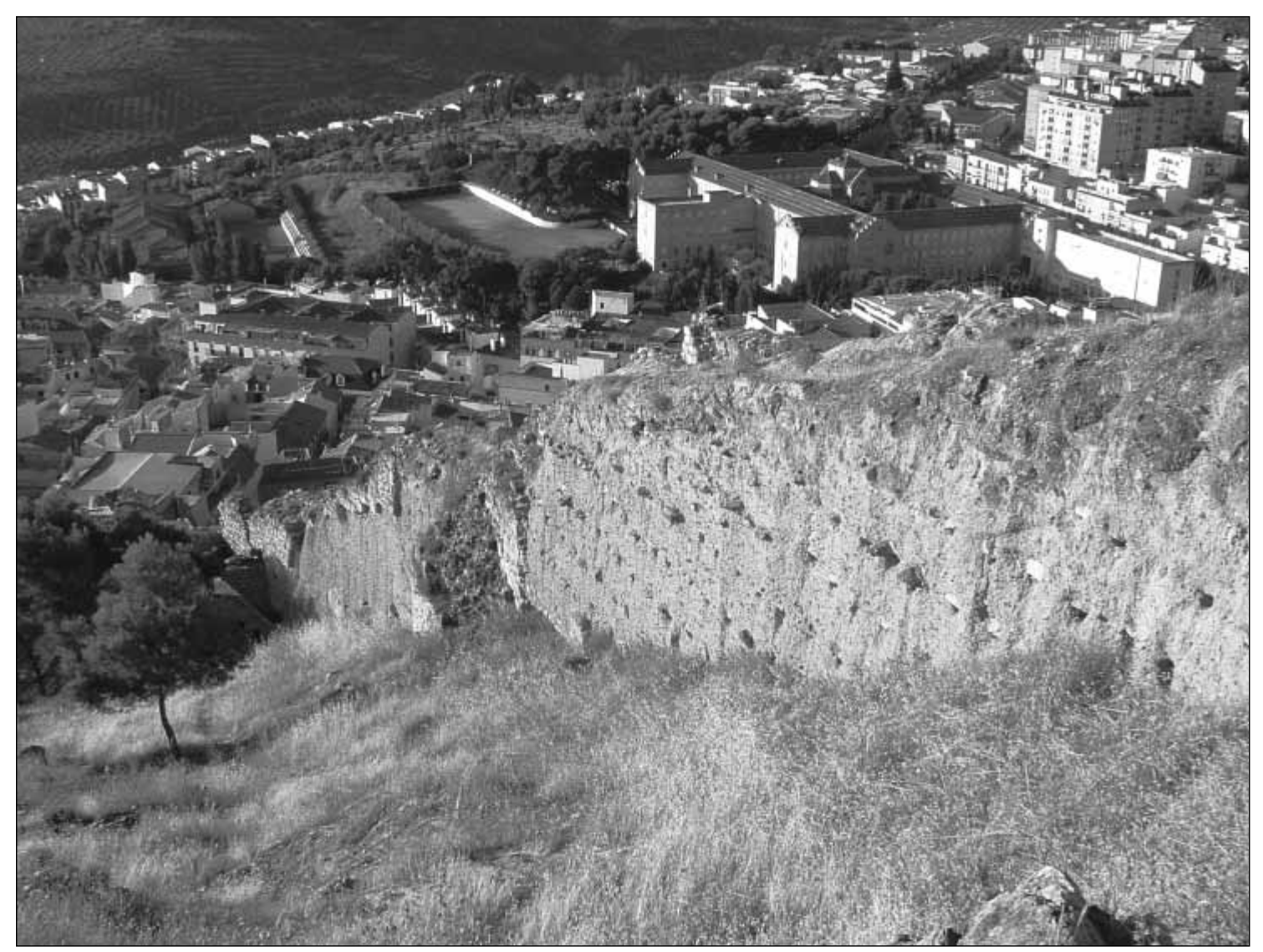

Lámina I4a. 


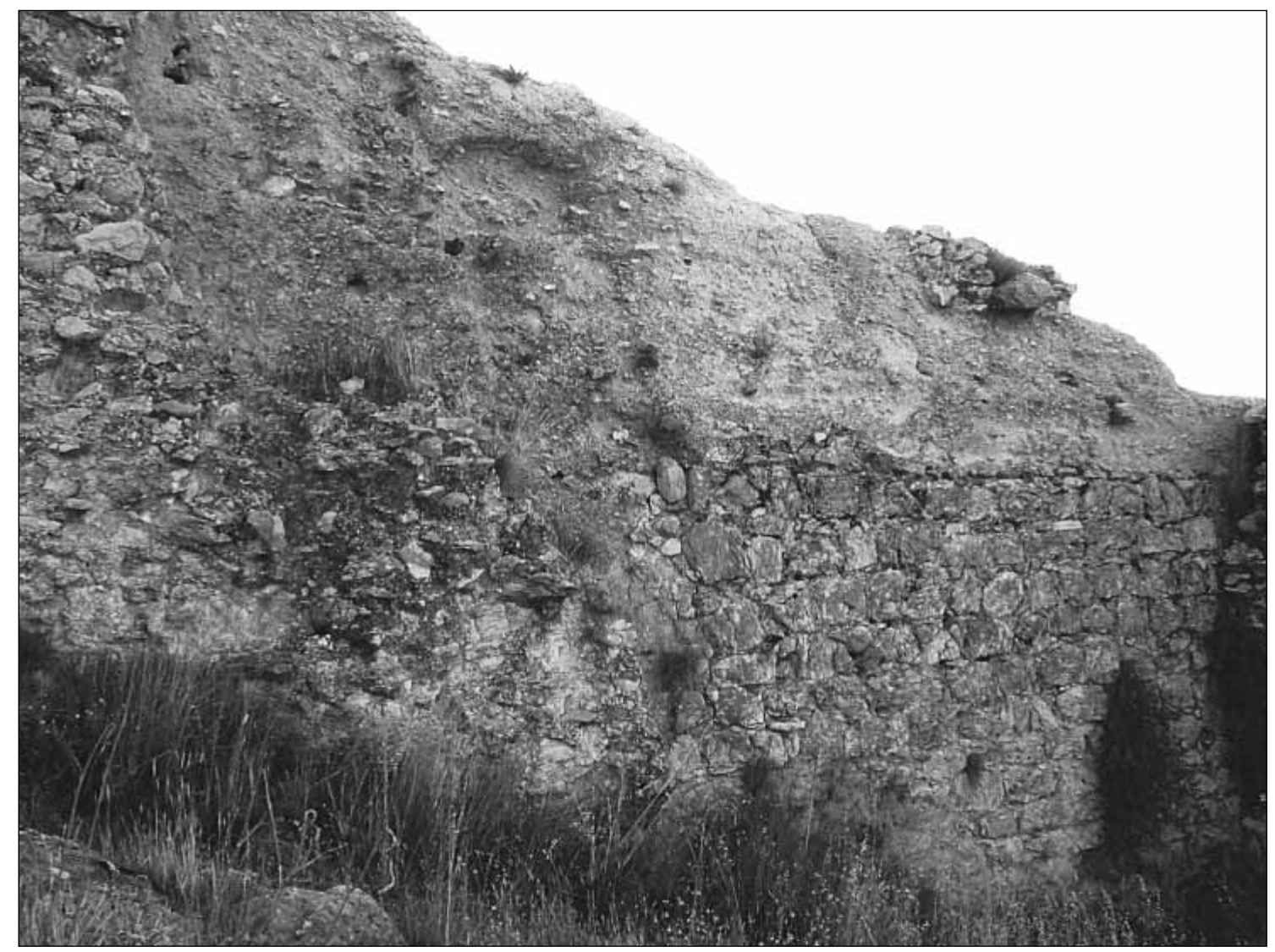

Lámina I4b.

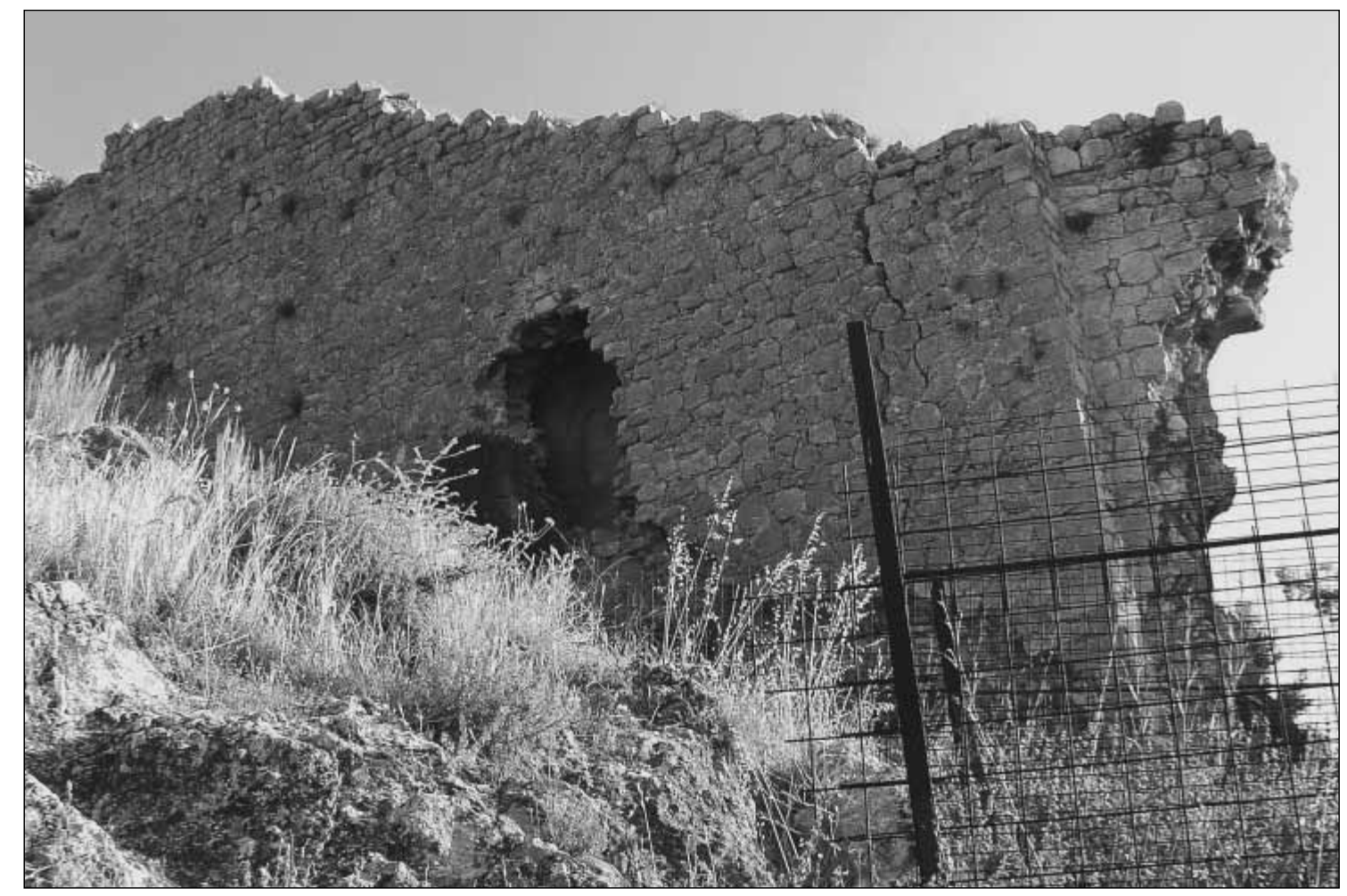

Lámina I4c. 


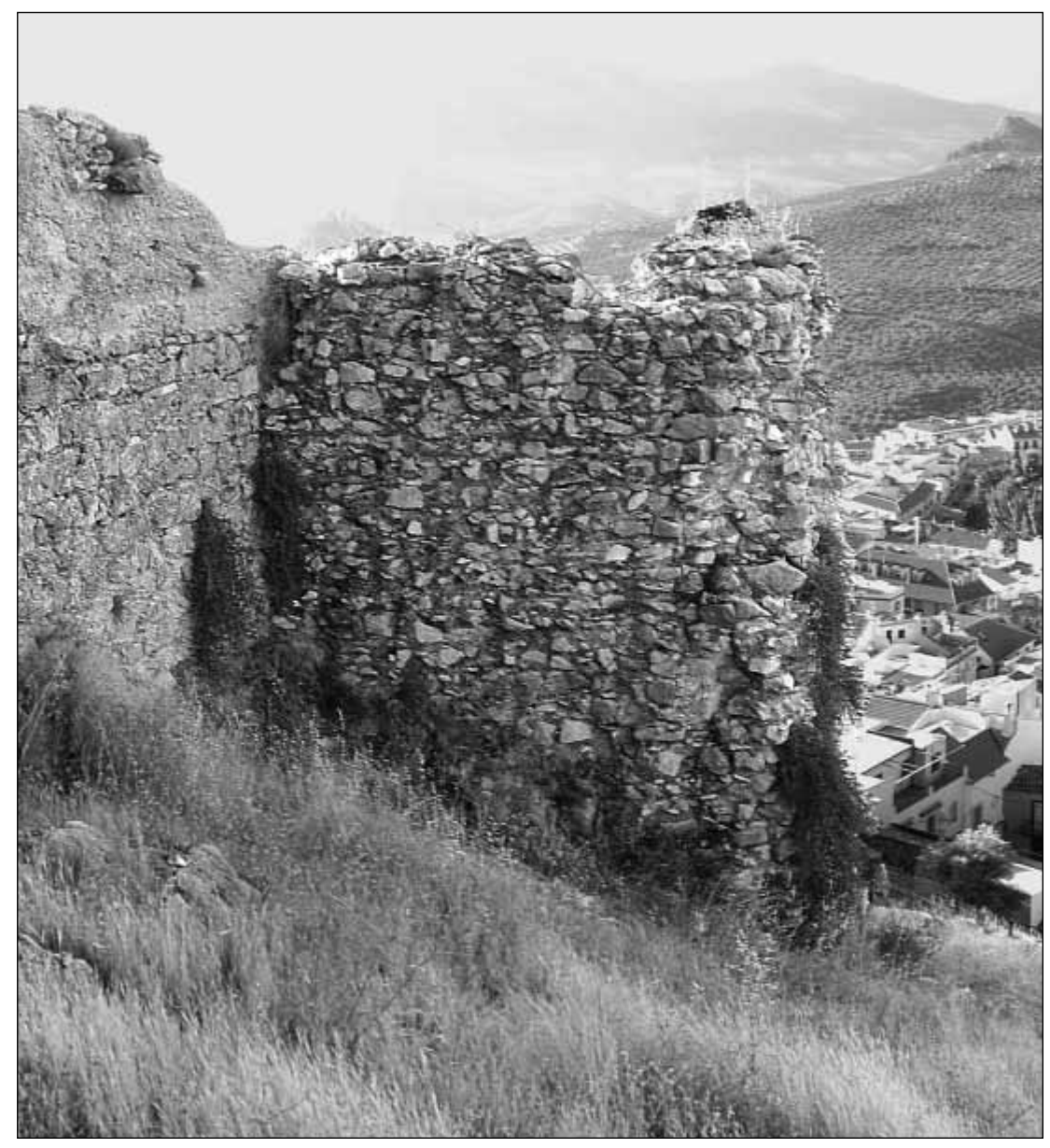

\section{Lámina I5a}

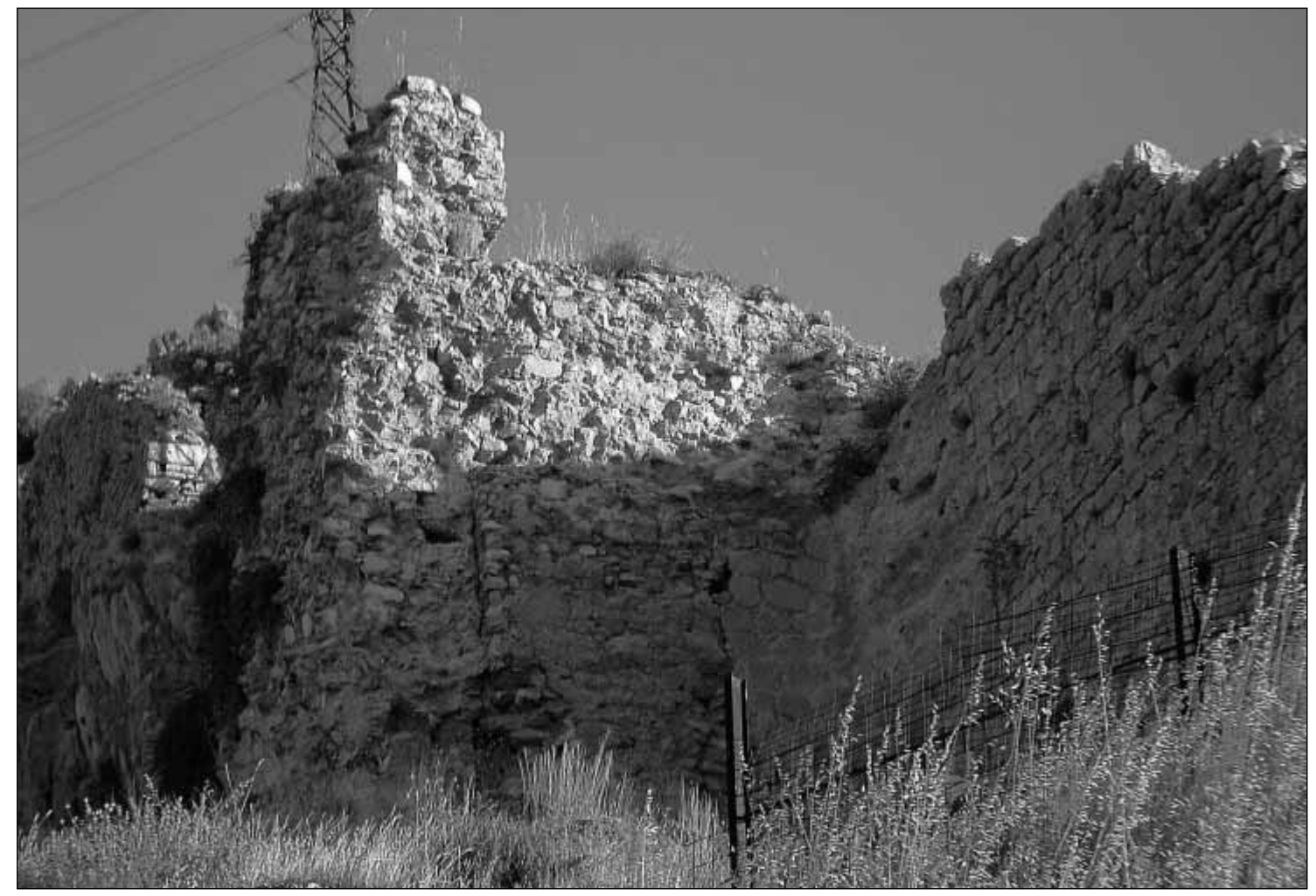

Lámina $15 b$. 


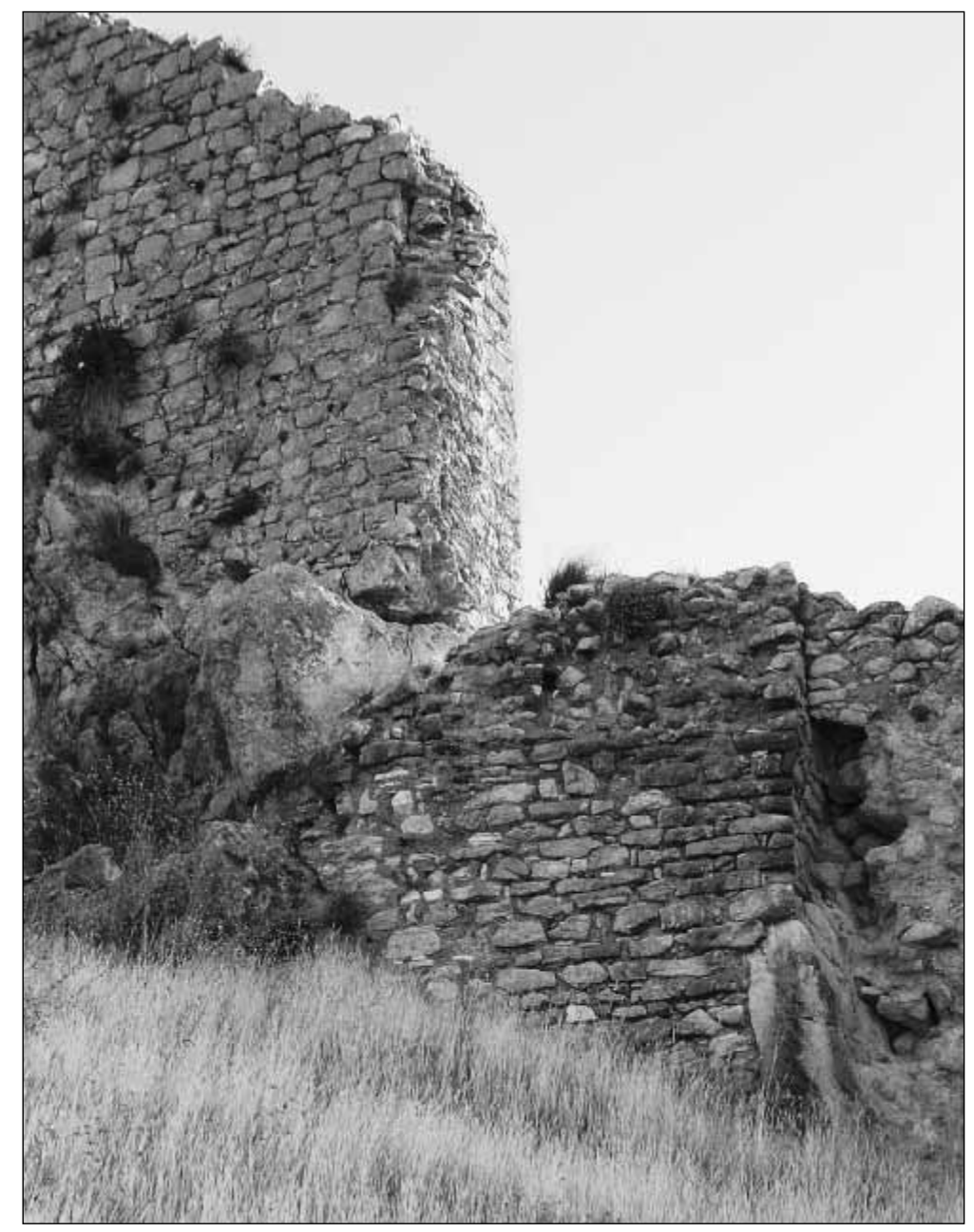

Lámina I6a

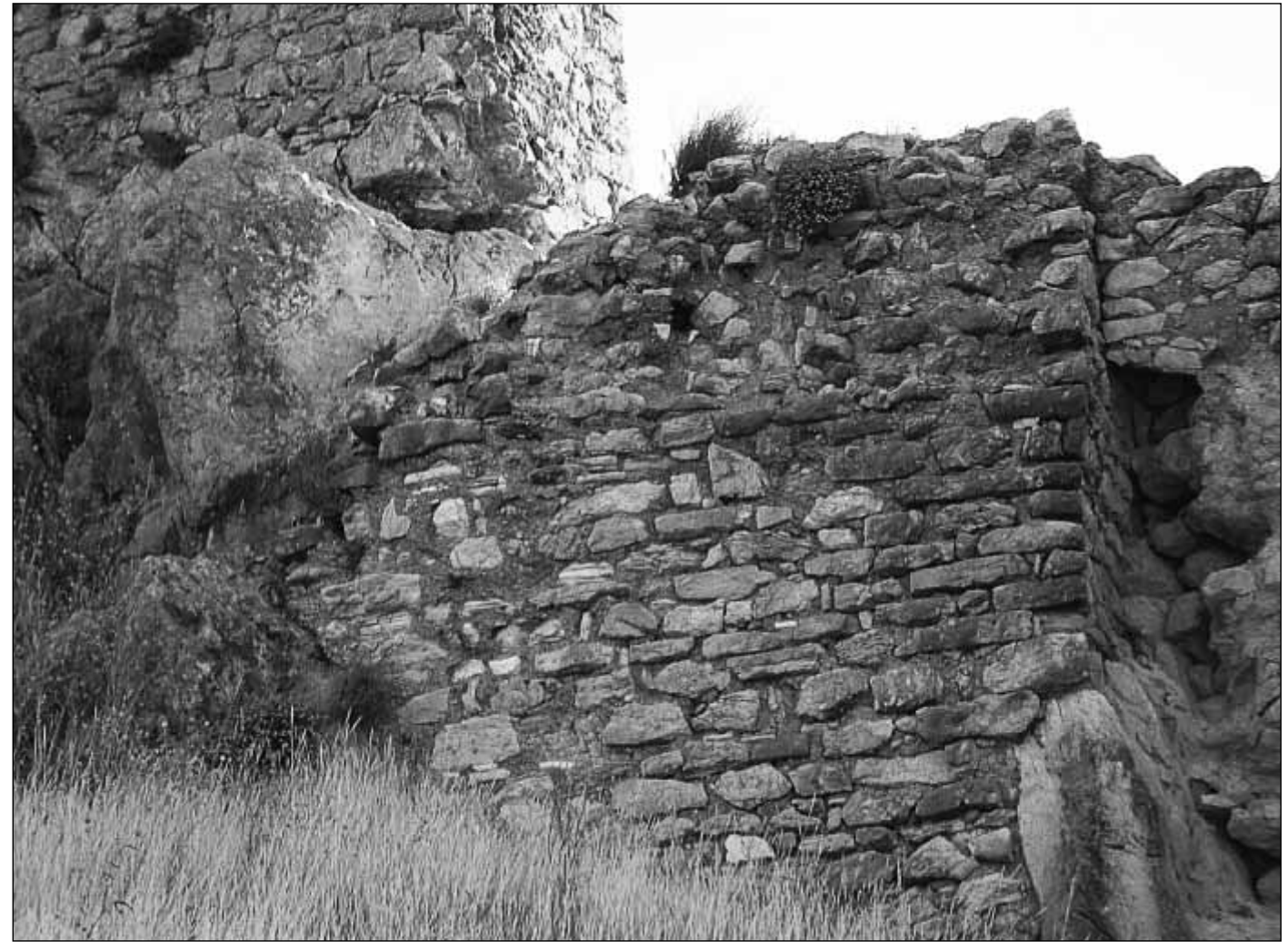




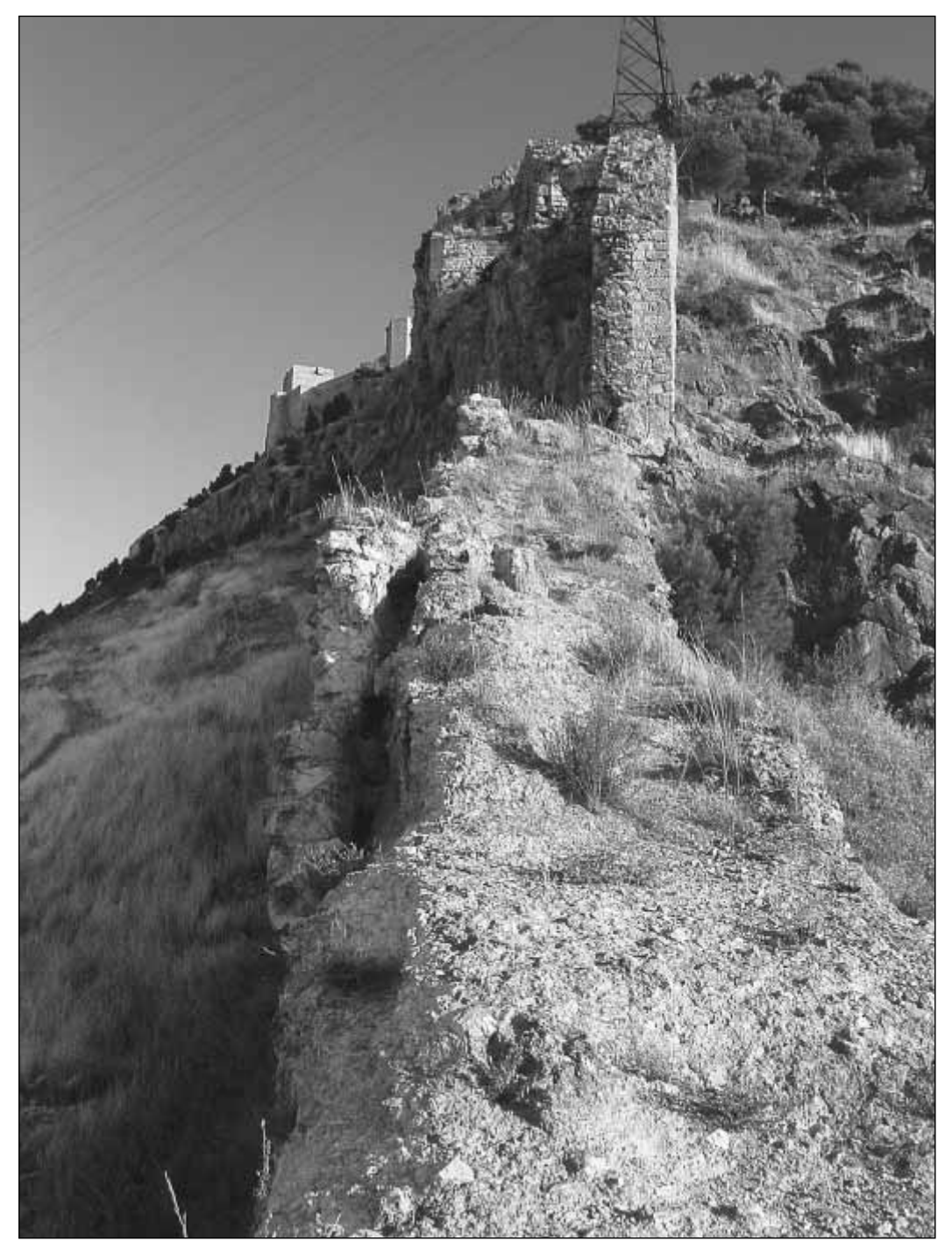

\section{Lámina 17.}




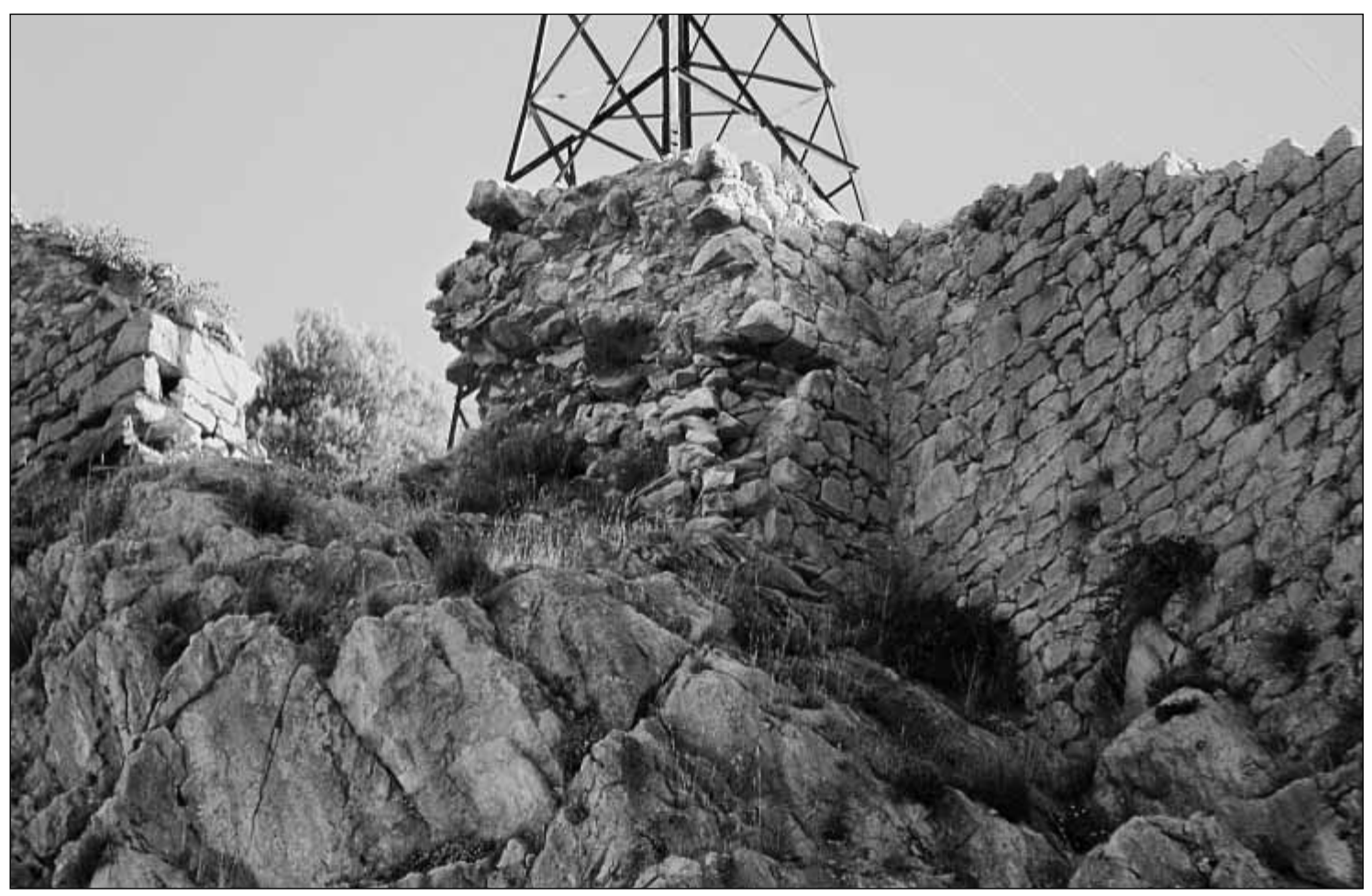

Lámina 19.

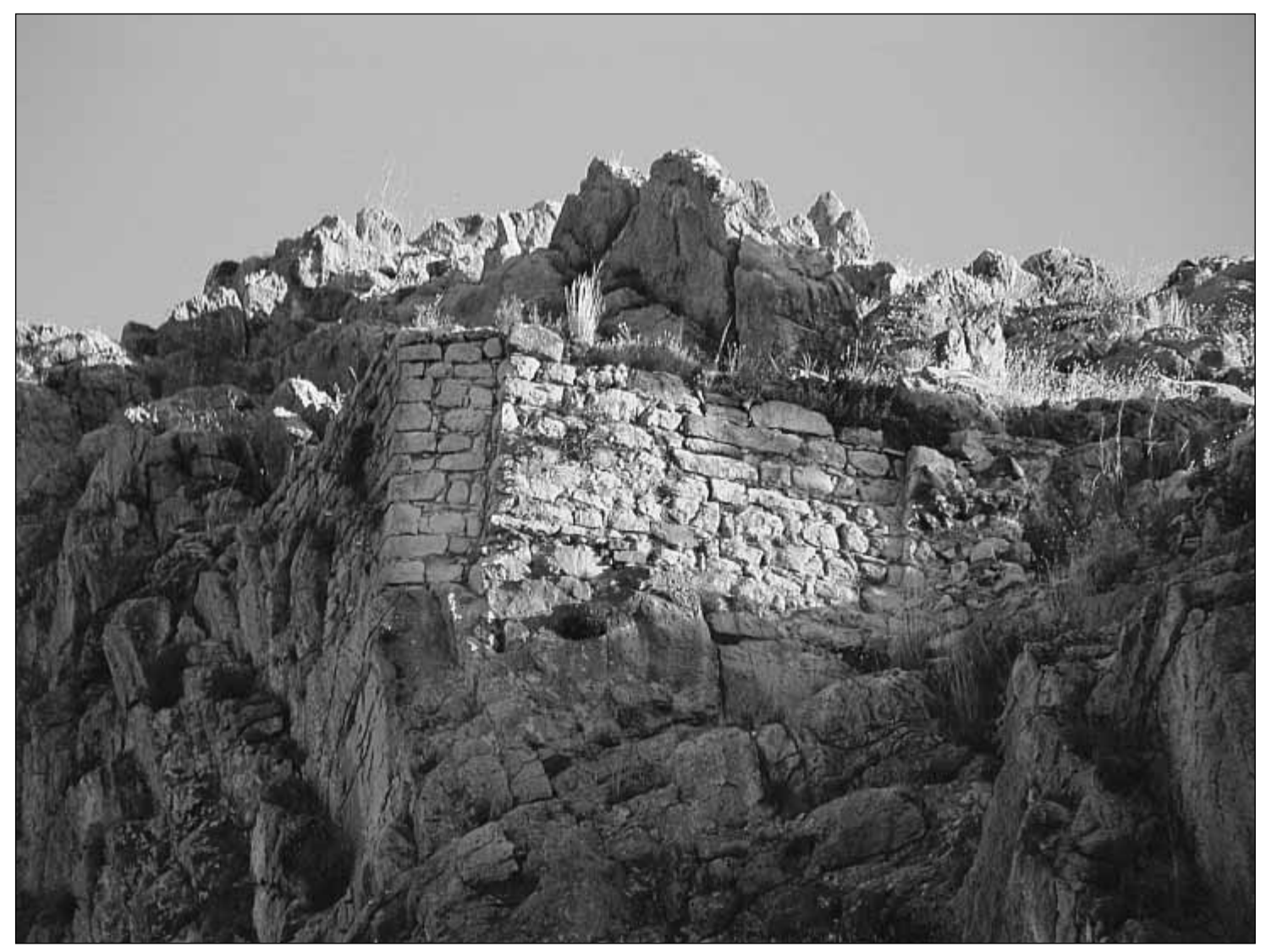

Lámina 20a. 


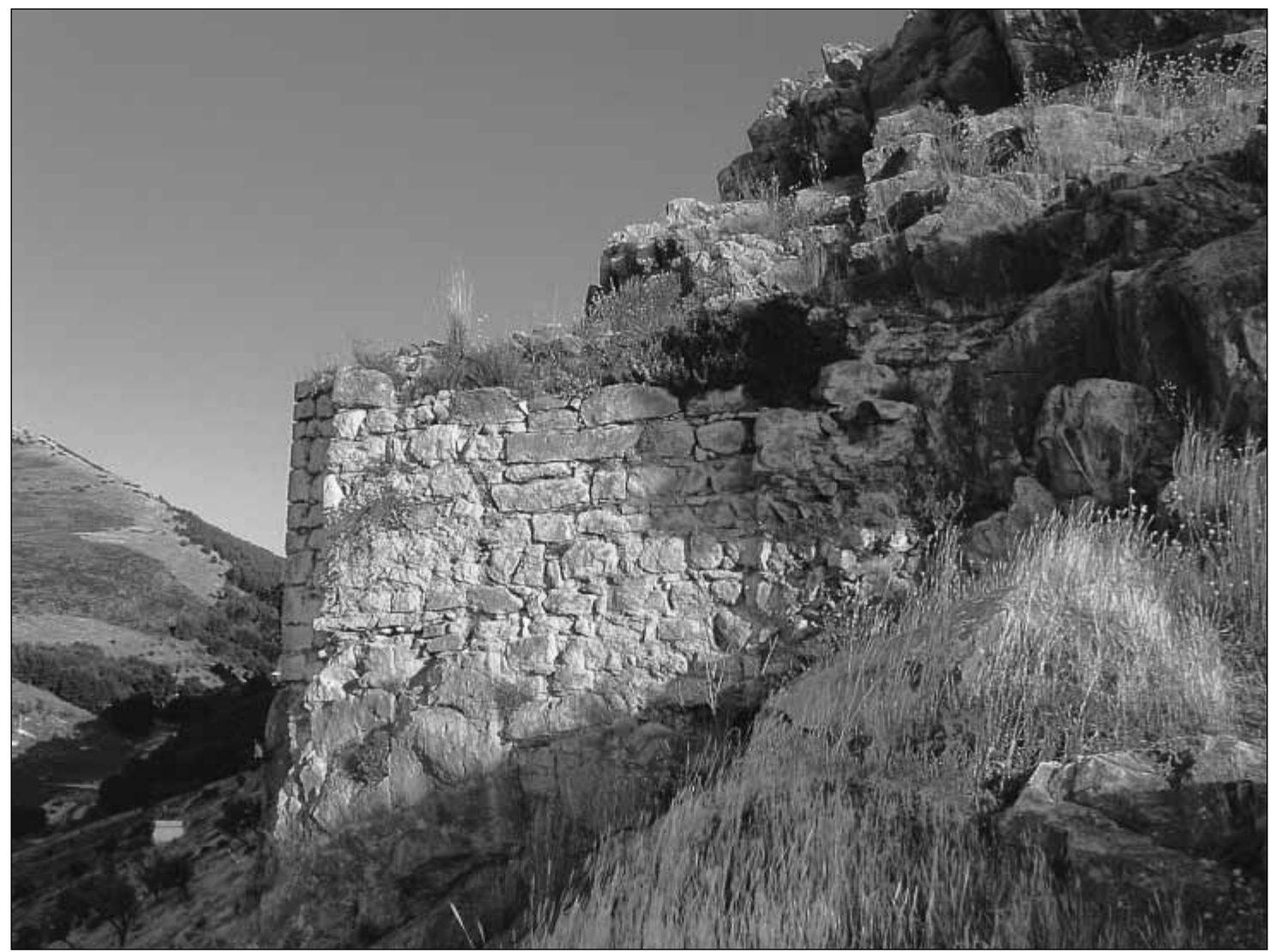

Lámina $20 b$. 